\title{
Polyethylene Hydrogenolysis at Mild Conditions over Ruthenium on Tungstated Zirconia
}

Cong Wang, Tianjun Xie, Pavel A. Kots, Brandon C. Vance, Kewei Yu, Pawan Kumar, Jiayi Fu, Sibao Liu, George Tsilomelekis, Eric A. Stach, Weiqing Zheng, and Dionisios G. Vlachos*

Cite This: JACS Au 2021, 1, 1422-1434

Read Online

\section{ACCESS |}

Џlll Metrics \& More

Article Recommendations

Supporting Information

ABSTRACT: Plastics waste has become a major environmental threat, with polyethylene being one of the most produced and hardest to recycle plastics. Hydrogenolysis is potentially the most viable catalytic technology for recycling. Ruthenium $(\mathrm{Ru})$ is one of the most active hydrogenolysis catalysts but yields too much methane. Here we introduce ruthenium supported on tungstated zirconia $(\mathrm{Ru}-\mathrm{WZr})$ for hydrogenolysis of lowdensity polyethylene (LDPE). We show that the Ru-WZr catalysts suppress methane formation and produce a product distribution in the diesel and wax/lubricant base-oil range unattainable by $\mathrm{Ru}-\mathrm{Zr}$ and other $\mathrm{Ru}$-supported catalysts. Importantly, the enhanced performance is showcased for real-world, single-use LDPE consumables. Reactivity

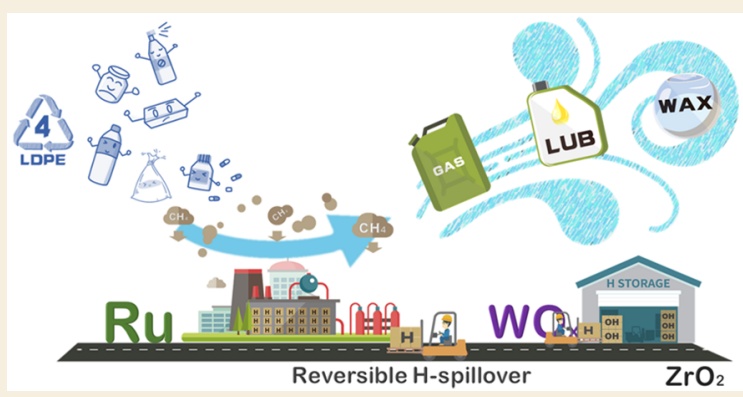
studies combined with characterization and density functional theory calculations reveal that highly dispersed $\left(\mathrm{WO}_{x}\right)_{\mathrm{n}}$ clusters store $\mathrm{H}$ as surface hydroxyls by spillover. We correlate this hydrogen storage mechanism with hydrogenation and desorption of long alkyl intermediates that would otherwise undergo further $\mathrm{C}-\mathrm{C}$ scission to produce methane.

KEYWORDS: plastic waste, hydrogenolysis, low-density polyethylene, ruthenium, tungstated zirconia, hydrogen spillover

\section{INTRODUCTION}

Over 12 billion tons of plastic waste are projected to end in landfills or leak into the environment by $2050 .{ }^{1}$ Roughly $60 \%$ of the global plastics are polyolefins, such as polyethylene and polypropylene, whose recycling rates are currently too low. ${ }^{2-4}$ The chemical composition and structure giving rise to the materials' desired properties, such as their stability, is the very reason their recycling is so challenging. Mechanical recycling and incineration are somewhat limited in scope for these plastics. Chemical recycling and specifically catalytic depolymerization is potentially attractive to combating polyolefin plastic waste. $^{5-12}$ Among approaches, catalytic cracking is facile, but it requires high reaction temperatures (typically above $673 \mathrm{~K}$ ), and is prone to low-value gas products. ${ }^{9,11,13-16}$ Olefin-mediated metathesis ${ }^{17}$ has recently been applied to polyethylene decomposition using a large volume of pentane and long residence times. ${ }^{6}$ Bifunctional hydrocracking has been proven feasible at moderate temperatures and $\mathrm{H}_{2}$ pressures. ${ }^{5,12,18-22}$ High branching imparts desirable properties to fuels and lubricants. However, it requires suitable catalysts to achieve appropriate metal-acid balance in strength and site density; ${ }^{12}$ the rate-limiting acid functionality often impedes high activities at lower temperatures.

Metal-catalyzed hydrogenolysis has recently drawn significant attention due to its decent reactivity and selectivity at low temperatures. Prior work has focused on discovering hydrogenolysis catalysts to produce fuels for proof-of-con- cept. ${ }^{6,8,23-26}$ For example, the hydrogenolysis of polyethylene over an ordered mesoporous shell/active site/core, $\mathrm{Pt} / \mathrm{SiO}_{2}$ catalyst was showcased to demonstrate a processive mechanism. ${ }^{27}$ Ruthenium-supported catalysts, e.g., $\mathrm{Ru} / \mathrm{C}^{24,26,28} \mathrm{Ru} /$ zeolites, ${ }^{29}$ and $\mathrm{Ru} / \mathrm{CeO}_{2}{ }^{23}$ possess higher activity than $\mathrm{Pt}^{8,25}$ and are potentially promising materials. Unfortunately, $\mathrm{Ru}$ generates significant methane, which is an undesirable, lowvalue product. Besides, most studies involve either a large catalyst-to-polymer ratio, long processing times, or solvents. Ultralow molecular weight plastics are commonly employed as substrates to enable high conversions at low temperatures. ${ }^{23,24}$ While exciting initial results have been obtained, there is a clear need for more active and selective catalysts to enable practical implementation.

Here we demonstrate that ruthenium on tungstated zirconia $(\mathrm{Ru}-\mathrm{WZr})$ is highly active for the hydrogenolysis of lowdensity polyethylene (LDPE, molecular weight, $\mathrm{Mw}, \sim 76 \mathrm{kDa}$ ) at mild conditions ( $523 \mathrm{~K}$ and 50 bar $\mathrm{H}_{2}$ for $2 \mathrm{~h}$ ). The deconstruction rate is fast, although a direct comparison to previous contributions is impossible due to different

Received: May 9, 2021

Published: August 30, 2021 

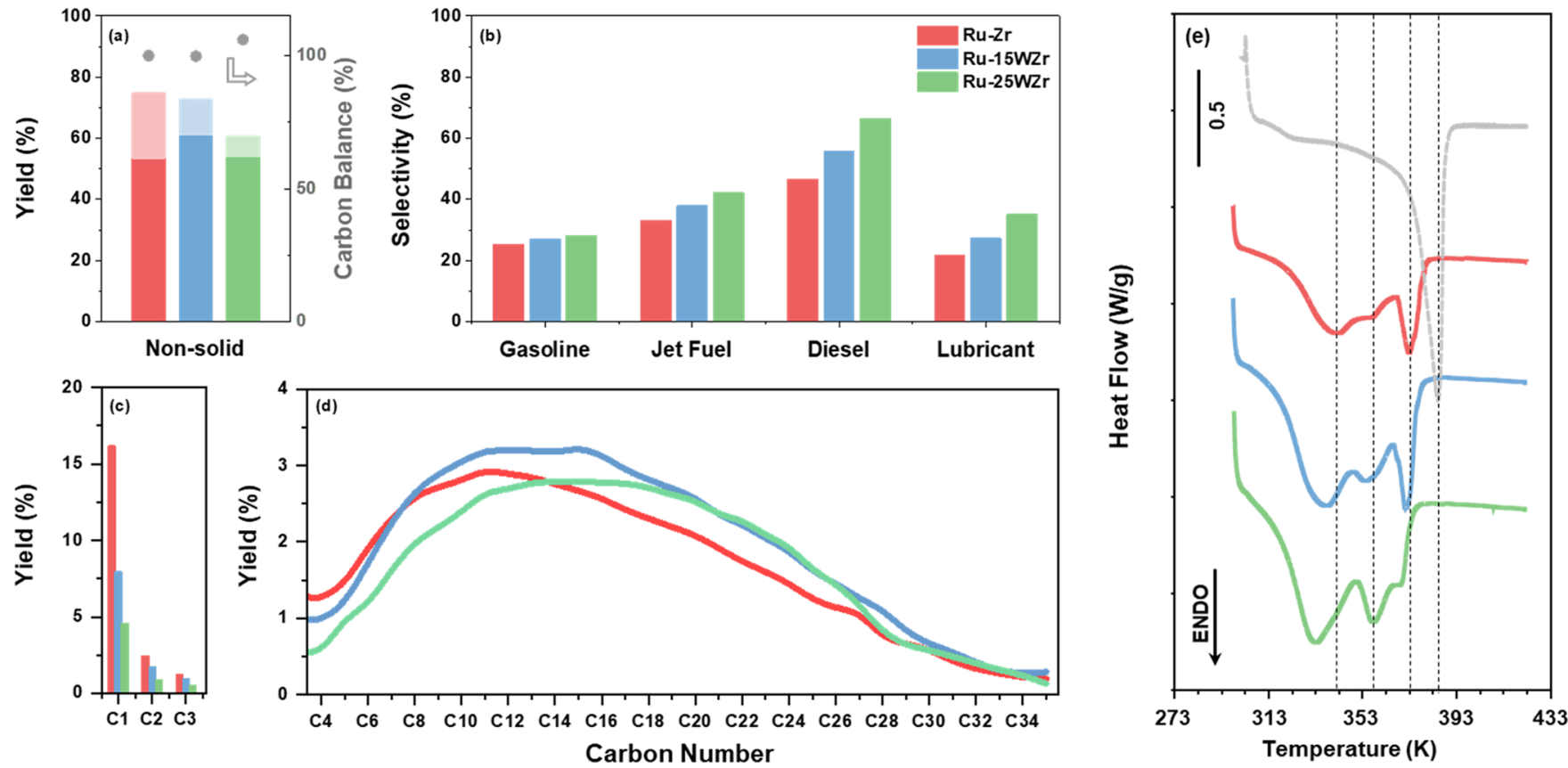

Figure 1. Effect of $\mathrm{WO}_{x}$ incorporation in Ru-WZr catalysts on LDPE hydrogenolysis. Yields and selectivities for LDPE hydrogenolysis over Ru-Zr (red), Ru-15WZr (blue), and Ru-25WZr (green) catalysts. a, Carbon balance (gray dots), yields of soluble (solid bars), and gaseous (faded bars) products. b, Selectivities by fuel range: gasoline, C5-C12; jet fuel, C8-C16; diesel, C9-C22; and waxes/lubricant base-oils, C20-C35. c and d, Detailed carbon distributions of the nonsolid products. e, Differential scanning calorimetry curves of the solid product residues referenced to pristine LDPE (gray curve). Auxiliary lines at 342, 358, 373, and $385 \mathrm{~K}$. Reactions performed at $523 \mathrm{~K}$ and 50 bar $\mathrm{H}_{2}$ for $2 \mathrm{~h}$ with $2 \mathrm{~g}$ of LDPE and $50 \mathrm{mg}$ of catalyst.

experimental conditions, substrates (especially regarding the large variability in molecular weight), and catalyst supports. Compared to $\mathrm{Ru}$ supported on bare zirconia (Ru-Zr), tungstated silica (Ru-WSi), HY zeolite (Ru-HY), and mesoporous [Al]MCM-41 (Ru-[Al]MCM-41) as benchmarks, the $\mathrm{Ru}-\mathrm{WZr}$ catalyst significantly suppresses methane; it produces a heavier and more valuable carbon product distribution for fuel and wax/lubricant base-oil. We hypothesize that excessive methane is primarily made via cascade surface reactions when hydrogenation and desorption of long alkanes are rate-limiting. Extensive catalyst characterization and density functional theory (DFT) calculations demonstrate highly dispersed $\left(\mathrm{WO}_{x}\right)_{\mathrm{n}}$ clusters that increase the $\mathrm{H}$ storage capacity in surface hydroxyls by spillover from $\mathrm{Ru}$ to $\mathrm{WO}_{x}$. We provide evidence for a strong correlation of the excess hydrogen storage and the hydrogenation of intermediates, possibly by reverse spillover, interfacial sites, and/or catalystpolymer interactions and desorption from the catalyst to avoid significant cracking leading to small hydrocarbons and methane. The implications for the rational design of polyolefin hydrogenolysis catalysts are discussed.

\section{RESULTS}

\section{LDPE Hydrogenolysis on Ru-WZr Catalysts}

We first demonstrate the promotional role of $\mathrm{WO}_{x}$ in $\mathrm{Ru}-\mathrm{WZr}$ catalysts on the mild hydrogenolysis of low-density polyethylene (LDPE, Mw $\sim 76 \mathrm{kDa}$ ). The operating conditions are rather mild, namely, a relatively low temperature of $523 \mathrm{~K}$ (250 ${ }^{\circ} \mathrm{C}$ ), ensuring depolymerization proceeds in the melt phase, a short processing time of $2 \mathrm{~h}$, and a low amount of catalyst (polymer to catalyst mass ratio of 40 ).

Figure 1 compares the product distributions over $\mathrm{Ru}-\mathrm{Zr}$, Ru$15 \mathrm{WZr}$, and Ru-25WZr catalysts (hereafter, the number in front of $\mathrm{W}$ indicates the weight percent of the added $\mathrm{WO}_{3}$ ). Overall, the catalysts are significantly active. The overall nonsolid (liquids plus gases) yield is relatively high given the mild conditions (Figure 1a: 75\%, 73\%, and 55\%, respectively) and is similar among catalysts, Ru-25WZr is less active but more selective to heavy liquids. Figure $1 \mathrm{a}-\mathrm{d}$ shows that $\mathrm{WO}_{x}$ has a profound effect on product distribution at similar conversions. It effectively decreases the gas yield from 21 to $7 \%$ and the undesired methane yield from $16 \%$ to $4.6 \%$. It consequently enhances the selectivity to liquids as follows: gasoline from $25 \%$ to $28 \%$, jet fuel from $33 \%$ to $42 \%$, diesel fuel from $47 \%$ to $66 \%$, and wax/lubricant base-oil from $22 \%$ to $35 \%$. The results obtained over Ru- $15 \mathrm{WZr}$ were benchmarked by good performing catalysts, $\mathrm{Ru}-\mathrm{Ce}$ and $\mathrm{Ru}-\mathrm{C}$, reported previously $^{23,24}$ (Figure S1 and the discussion in the Supporting Information). Effectively, the Ru-WZr catalysts shift the distribution to heavier, more valuable, soluble products (the peak of the distribution shifts from C11 to C15). We elaborate with extensive characterizations that the apparent reaction rate of the Ru-WZr catalysts is affected by the interplay of reduced $\mathrm{Ru}$ site density and an increased turnover frequency and is comparable to that on $\mathrm{Ru}-\mathrm{Zr}$. The key difference between catalysts (Figure 1) is in selectivity.

Differential scanning calorimetry (DSC) of the solid residue (Figure 1e) and pristine LDPE (melting temperature, $T_{\mathrm{m}} \sim$ $385 \mathrm{~K}$ ) shows that the leftover solid over $\mathrm{Ru}-\mathrm{Zr}$ possesses a low-temperature broad feature centered at $342 \mathrm{~K}$, a shoulder at $358 \mathrm{~K}$, and a high-temperature sharp feature centered at $373 \mathrm{~K}$. These features are assigned to $\mathrm{C} 20-\mathrm{C} 35, \mathrm{C} 35-\mathrm{C} 50$, and C50-C100 products, respectively. ${ }^{30-33}$ The DSC features over $\mathrm{Ru}-15 \mathrm{WZr}$ and $\mathrm{Ru}-25 \mathrm{WZr}$ shift progressively to lower temperatures with increasing $\mathrm{WO}_{x}$ loading, indicating a solid consisting of shorter chains. Conversely, the corresponding 

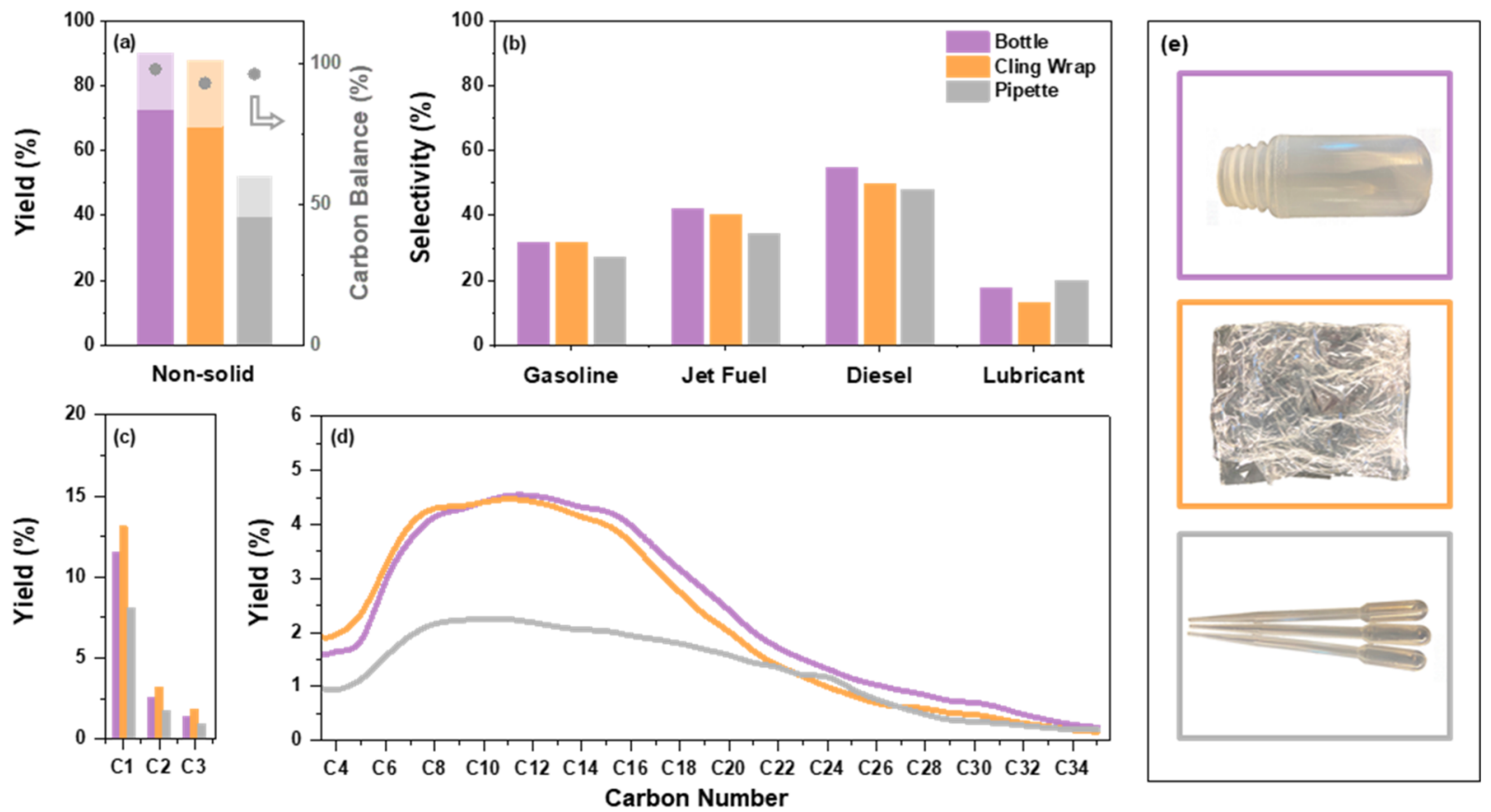

Figure 2. Hydrogenolysis of real-world consumable LDPE plastics over the Ru-15WZr catalyst. Yields and selectivities for hydrogenolysis of singleuse LDPE bottle (purple), cling wrap (orange), and laboratory pipettes (gray) over the Ru-15WZr catalyst. a, Carbon balance (gray dots) and yields of soluble (solid bars) and gaseous (faded bars) products. b, Selectivities by fuel range: gasoline, C5-C12; jet fuel, C8-C16; diesel, C9C22; and waxes/lubricant base-oils, C20-C35. c and d, Detailed carbon distributions of the nonsolid products. e, Images of the single-use plastics. Reactions performed at $523 \mathrm{~K}$ and $50 \mathrm{bar}_{2}$ with $2 \mathrm{~g}$ of LDPE and $50 \mathrm{mg}$ of catalyst for $2 \mathrm{~h}$ for the bottle, $1.5 \mathrm{~h}$ for the cling wrap, and $1.25 \mathrm{~h}$ for the pipettes to reduce the conversion to below $100 \%$ nonsolid yield.

nonsolid is heavier (Figure 1c,d), indicating a heavier carbon distribution of the products. Reduction in the melting temperature may also result from varying branching degrees; ${ }^{34}$ we rule out this possibility due to forming mainly normal alkanes with low branching (Table S1). Excitingly, Figure 1 demonstrates that $\mathrm{WO}_{x}$ modification of the $\mathrm{Ru}-\mathrm{WZr}$ catalysts can suppress methane formation and shift the carbon distribution to larger, value-added alkanes, such as diesel and wax/lubricant base-oils. $\mathrm{WO}_{x}$ modification overcomes an essential barrier of the otherwise excellent $\mathrm{Ru}$ catalyst reported in other works and does so at short times and low temperatures.

Excitingly, hydrogenolysis of real-world, single-use plastic consumables, such as LDPE bottles, cling wraps, and pipettes (Figure 2e), over the Ru-15WZr catalyst gave near quantitative conversion (Figure 2a), with selective product distributions (Figure $2 b-d$ ) similar to that of the pristine LDPE shown in Figure 1.

\section{Structural Characterization of Ru-WZr Catalysts}

High magnification BF-TEM, HAADF-STEM, and EDS elemental mapping of the Ru-15WZr (Figure 3) and $\mathrm{Ru}-\mathrm{Zr}$ (Figure S2) catalysts shows that the $\mathrm{Ru}-\mathrm{Zr}$ has a characteristic mesoporous structure of around $10 \mathrm{~nm}$ diameter (Figure S2a) and $\sim 1-5 \mathrm{~nm} \mathrm{Ru}$ nanoparticles (Figure S2c,d) consistent with BET (Table S2) and $\mathrm{H}_{2}$ titration data (Table S3). In situ EXAFS results (Table S4) show that the $\mathrm{Ru}-\mathrm{Ru}$ coordination numbers of the reduced $\mathrm{Ru}-\mathrm{Zr}$ and $\mathrm{Ru}-15 \mathrm{WZr}$ catalysts are 8.3 and 6.6, respectively, which indicate that the $\mathrm{Ru}$ particle size decreases on average only slightly with the WZr support. ${ }^{35}$

Distinguishing $\mathrm{Ru}$ from $\left(\mathrm{WO}_{x}\right)_{\mathrm{n}}$ in $\mathrm{Ru}-15 \mathrm{WZr}$ based on the TEM contrast is challenging due to similar atomic numbers. However, the surface roughness of $\mathrm{Ru}-15 \mathrm{WZr}$ (Figure 3a,b) and $\mathrm{Ru}-\mathrm{Zr}$ (Figure S2a,b) indicates that the highly dispersed $\sim 1 \mathrm{~nm}$ clusters in the former are most likely $\left(\mathrm{WO}_{x}\right)_{\mathrm{n}}{ }^{39}$ HAADF-STEM images (Figure 3e,f), XRD (Figure S3a), and STEM-EDS mapping (Figure $3 \mathrm{~g}$ ) further confirm the high dispersion of $\mathrm{Ru}$ nanoparticles and $\left(\mathrm{WO}_{x}\right)_{\mathrm{n}}$ clusters. Intriguingly, a $\mathrm{Ru}$ particle depicted in Figure $3 \mathrm{c}$ is partially covered with an overlayer, identified as a $\mathrm{WO}_{x}$ cluster, using the lattice parameter ${ }^{36-38}$ (Figure $3 \mathrm{~d}$ ). This suggests that the $\left(\mathrm{WO}_{x}\right)_{\mathrm{n}}$ species are mobile ${ }^{40}$ and may redisperse onto the metal of $\mathrm{Ru}$ during impregnation/reduction. Ambient temperature Raman spectra (Figure S3b) confirmed that the $\left(\mathrm{WO}_{x}\right)_{\mathrm{n}}$ species are highly amorphous and lack $\mathrm{WO}_{3}$ crystalline structure in the presence of Ru. Furthermore, the HAADFSTEM data and EDS Ru and $\mathrm{W}$ maps shown in Figure $3 \mathrm{~g}$ indicate that the two elements show substantial spatial overlap. These partial overlayers significantly decrease the $\mathrm{Ru}$ site density when increasing $\mathrm{WO}_{x}$ loading (Table S3). However, the LDPE reactivity on $\mathrm{Ru}-\mathrm{WZr}$ catalysts does not decrease as much (Figure 1a), suggesting that $\mathrm{WO}_{x}$ enhances the $\mathrm{Ru}$ turnover rate.

The $15 \mathrm{WZr}$ sample has a $\mathrm{WO}_{x}$ surface density $(\sim 6.6 \mathrm{~W} /$ $\mathrm{nm}^{2}$, Table S2) corresponding close to a monolayer coverage. ${ }^{41,42} \mathrm{WO}_{3}$ crystallites are nearly absent in the XRD or Raman spectra (Figure S4a,b). Unlike $\mathrm{ZrO}_{2}$ with a tetragonal or monoclinic structure, $\mathrm{ZrO}_{2}$ in $15 \mathrm{WZr}$ is predominantly tetragonal (Figure S4a). Characteristic Raman bands in $\mathrm{ZrO}_{2}$ decrease significantly with increasing $\mathrm{W}$ loading (Figure S4b), suggesting a high $\mathrm{WO}_{x}$ coverage. The $25 \mathrm{WZr}$ sample has similar structural features except for $\mathrm{WO}_{3}$ crystallites seen in $\mathrm{XRD}$ and Raman spectra (Figure S4a,b) due to a higher loading $\left(\sim 10.7 \mathrm{~W} / \mathrm{nm}^{2}\right.$, Table S2; more than one monolayer coverage). The $15 \mathrm{WZr}$ sample exhibits Brønsted acidity based on pyridine adsorption (Figure S4c), and $\mathrm{Ru}$ does not 

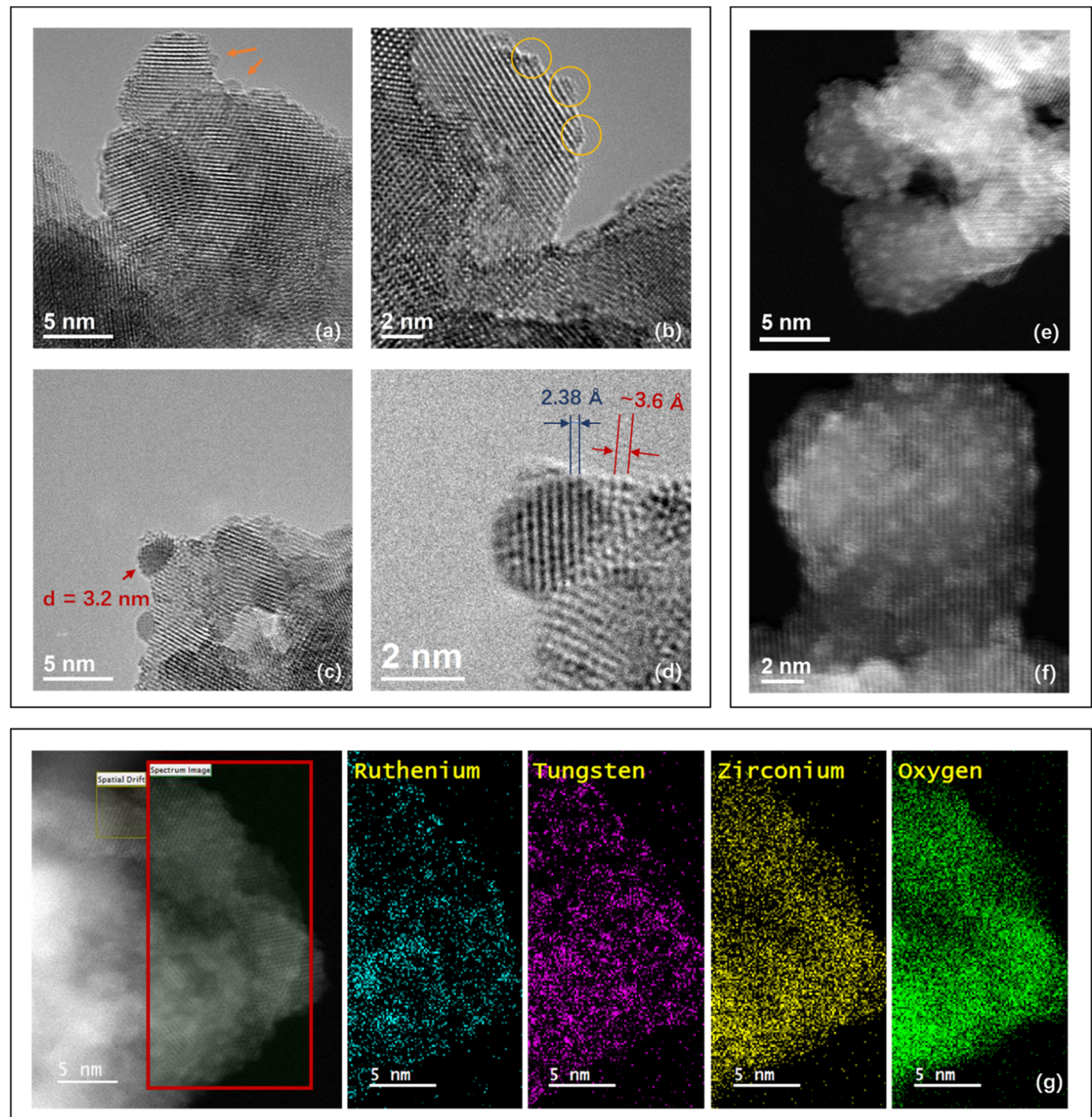

Figure 3. Structural characterization of Ru-15WZr catalyst. a, TEM image of Ru-15WZr showing a rough surface consisting of Ru nanoparticles (arrows) and $\sim 1 \mathrm{~nm}\left(\mathrm{WO}_{x}\right)_{\mathrm{n}}$ clusters. b, High magnification image showing $\sim 1 \mathrm{~nm}$ surface clusters (circles). c, Representative Ru hemispherical particle partially covered by an overlayer. d, High magnification image indicating a lattice spacing of $2.38 \AA$, consistent with $\mathrm{Ru}(100){ }^{36}$ and a lattice spacing of $\sim 3.6 \AA$ of the overlayer, consistent with monoclinic $\mathrm{WO}_{3}{ }^{37,38}$ e and f, DF-STEM images of Ru-15WZr indicating a uniform distribution of the $\sim 1 \mathrm{~nm} \mathrm{WO}_{x}$ clusters. $\mathrm{g}$, STEM-EDS elemental mapping of the Ru-15WZr catalyst.

significantly affect the acidity of the $15 \mathrm{WZr}$ support (Figure S4d). However, the Ru-15WZr shows negligible isomerization activity (Table S1), suggesting a lack of metal-acid bifunctional hydrocracking-hydroisomerization chemistry. Compared to the bifunctional Pt-WZr catalyst we reported recently, which promotes a high degree of branching, ${ }^{19,43} \mathrm{Ru}$ is much more active for deep dehydrogenation and subsequent $\mathrm{C}-\mathrm{C}$ scission due to stronger metal-carbon bond strength. ${ }^{44,45}$ This prevents $\mathrm{Ru}$ from producing olefins that undergo hydrocracking and isomerization over the Brønsted acid sites. ${ }^{46}$ Two additional $\mathrm{Ru}$ catalysts on highly acidic $\mathrm{HY}\left(\mathrm{Si} / \mathrm{Al}_{2}=30\right)$ zeolite and mesoporous $[\mathrm{Al}] \mathrm{MCM}-41\left(\mathrm{Si} / \mathrm{Al}_{2}=25\right)$ were prepared to understand the role of acidity. Moderate branching (Table S5) was observed, likely due to the stronger Brønsted acid strength ${ }^{47}$ and much greater site density of these supports. ${ }^{19}$ However, these catalysts are not as active (56\% and $68 \%$ conversion over $\mathrm{Ru}-\mathrm{HY}$ and $\mathrm{Ru}-[\mathrm{Al}] \mathrm{MCM}-41$, respectively) and produce much higher methane yields (36\% and $52 \%$, respectively) compared to $\mathrm{Ru}-15 \mathrm{WZr}$ under identical conditions. These findings suggest that acidity is not as critical a factor to methane suppression over the Ru-WZr catalysts.

Proposed Reaction Mechanism over Ru-WZr Catalysts

The time evolution for LDPE hydrogenolysis over Ru-15WZr is depicted in Figure 4. The data exhibits characteristic sequential reactions converting longer alkanes to shorter ones, evidenced by bell-shaped trajectories of $\mathrm{C} 20+, \mathrm{C} 17-\mathrm{C} 19$, and $\mathrm{C} 13-\mathrm{C} 16$ (longer molecules reach maxima at shorter times), with a monotonic growth of $\mathrm{C} 8-\mathrm{C} 12, \mathrm{C} 5-\mathrm{C} 7$, and $\mathrm{C} 1-\mathrm{C} 4$. The nonsolid products progressively shift toward lower molecular weights (Figure 4c,d). Methane becomes dominant (20\% yield) only at long reaction times after severe overreaction due to the sequential nature of the reaction. Noticeably, the nonsolid yields experience a 10 -fold increase from $7 \%$ to $73 \%$ between 1 to $2 \mathrm{~h}$ (Figure $4 \mathrm{a}$ ). In this time 

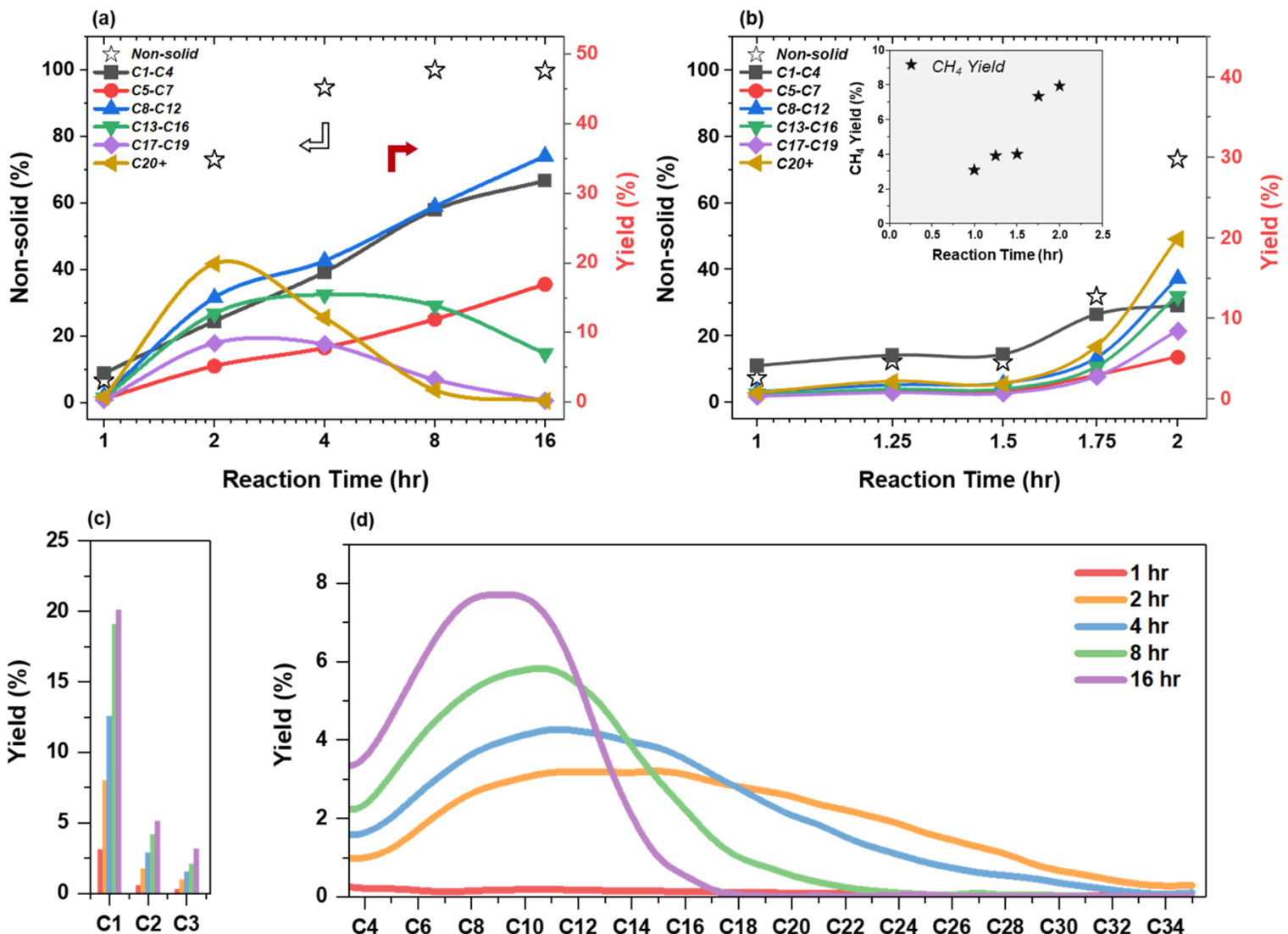

(d)

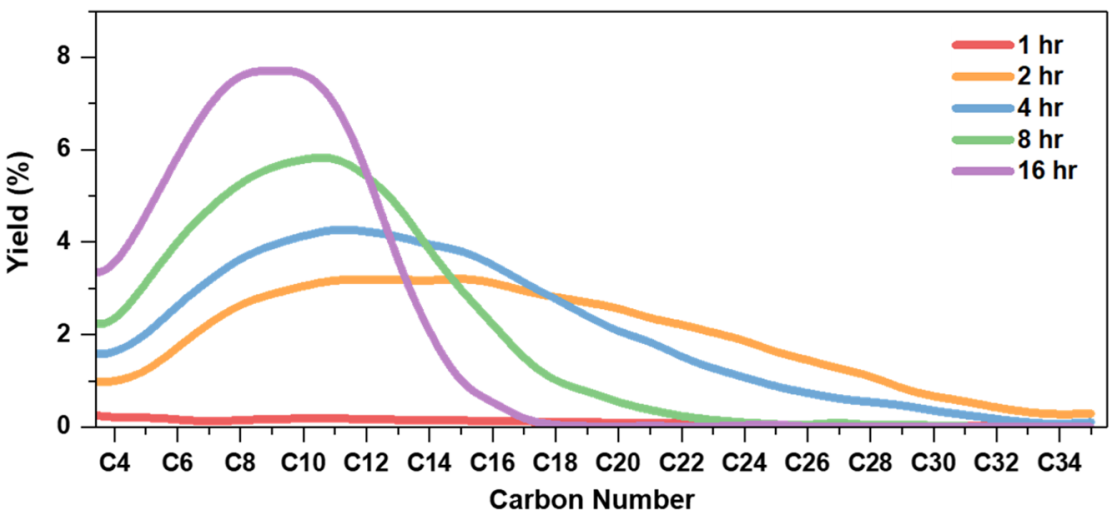

Figure 4. Reaction time analysis on Ru-15WZr. Time evolution of nonsolid yields in LDPE hydrogenolysis over Ru-15WZr catalysts. Reactions performed at $523 \mathrm{~K}$ and 50 bar $\mathrm{H}_{2}$ for $1-16 \mathrm{~h}$ with $2 \mathrm{~g}$ of LDPE over $50 \mathrm{mg}$ of catalyst. a, Yields at $1-16 \mathrm{~h}$. b, Yields at $1-2 \mathrm{~h}$; the inset shows the time evolution of methane yield. $\mathrm{c}$ and d, Detailed carbon distributions of the nonsolids at the times indicated.

interval, further experiments (Figure $4 \mathrm{~b}$ ) reveal a light-off in nonsolid yields between 1.5 and $1.75 \mathrm{~h}$ (from $12 \%$ to $32 \%$ ). TEM images of postreaction ( $2 \mathrm{~h}$ ) catalyst (Figure S5) show no noticeable morphological or size change in $\mathrm{Ru}$ and $\left(\mathrm{WO}_{x}\right)_{\mathrm{n}}$ clusters compared to the fresh sample (Figure $3 a-d)$. No sudden changes in the solid DSC curves occur at this time interval (Figure S6), i.e., the melt of the LDPE is steadily depolymerized. This indicates the hydrogenolysis product distribution swiftly shifts to lower carbon numbers in the early stages of the reaction and becomes GC detectable in the C1C35 carbon range after $1.5 \mathrm{~h}$ (Figure $4 \mathrm{~b}$ ). At $1 \mathrm{~h}$, the yield of $\mathrm{C} 1-\mathrm{C} 35$ alkanes is only $7 \%$ (of which methane is $3 \%$ ); during this time, the LDPE ( Mw $\sim 76 \mathrm{kDa})$ is substantially decomposed to the $\sim \mathrm{C} 300$ range (estimated from the $\mathrm{Mw}$ of $\sim 4 \mathrm{kDa}$ LDPE standard).

Notably, methane is produced in disproportionally large fractions early on (Figure 4b), and its yield increases relatively linearly with time (inset in Figure 4b), indicating its parallel production with the hydrogenolysis of long alkanes. Continuous flow hydrogenolysis experiments using $n$-hexane as a surrogate are consistent with this hypothesis (Figure S7, see discussion in Supporting Information), whereby methane forms via a cascade of multiple $\mathrm{C}-\mathrm{C}$ bond scissions within one $n$-hexane turnover. Hereby, we propose that methane forms through a cascade hydrogenolysis mechanism illustrated in Scheme 1a. The first $\mathrm{C}-\mathrm{C}$ bond scission (ii) is initiated following dehydrogenation (i). ${ }^{44}$ The hydrogenation/desorption (iii) of reaction intermediates is rate-limiting, especially for long alkyls in hydrogen deficient environments. As a result, these surface species undergo multiple $\mathrm{C}-\mathrm{C}$ bond scissions $(i v-v)$ before hydrogenation and desorption (vi). Since these intermediates are bound to the $\mathrm{Ru}$ surface with newly formed terminal carbons (ii), further $\mathrm{C}-\mathrm{C}$ bond breaking favors demethylation to make methane (iv-vii). $\mathrm{Ru}$ catalysts favor terminal $\mathrm{C}-\mathrm{C}$ bond breaking even in the primary $\mathrm{C}-\mathrm{C}$ scission (i-iii). ${ }^{48-50}$ The proposed cascade mechanism (ivvii) must be invoked in the decomposition to rationalize the disproportionally high methane yields in both LDPE and model hexane reactions consistent with recent contributions. $^{24,29}$

Catalytic performance at various hydrogen pressures supports this mechanism (Figures S8-S10, see detailed discussion in Supporting Information). Activities and selectivities (lower methane yield and heavier product distributions) increase over $\mathrm{Ru}-\mathrm{Zr}$ and $\mathrm{Ru}-15 \mathrm{WZr}$ catalysts with increasing $\mathrm{H}_{2}$ pressure. A higher $\mathrm{H}_{2}$ pressure promotes the rate-limiting hydrogenation of intermediates followed by their desorption (iii), thereby enhancing the apparent rate and suppressing methane formation (iv-vii).

We hypothesize that the promotional effect of $\mathrm{WO}_{x}$ (Figure 1) may share the same origin as the hydrogen pressure. Indeed, the benefit of high $\mathrm{H}_{2}$ pressure diminishes with increasing $\mathrm{WO}_{x}$ loading (Figure S10). At sufficiently high $\mathrm{H}_{2}$ pressure, such as 130 bar, the hydrogenation/desorption (iii) step no longer limits the overall rate. The product distributions on $\mathrm{Ru}-$ $\mathrm{Zr}$ and $\mathrm{Ru}-15 \mathrm{WZr}$ become similar at comparable conversions (Figure S8g,h) with rates proportional to their Ru site density (123 and $76 \mu \mathrm{mol} / \mathrm{g}$, respectively, Table S3). This suggests 
Scheme 1. Schematic of the Proposed Reaction Mechanisms ${ }^{a}$
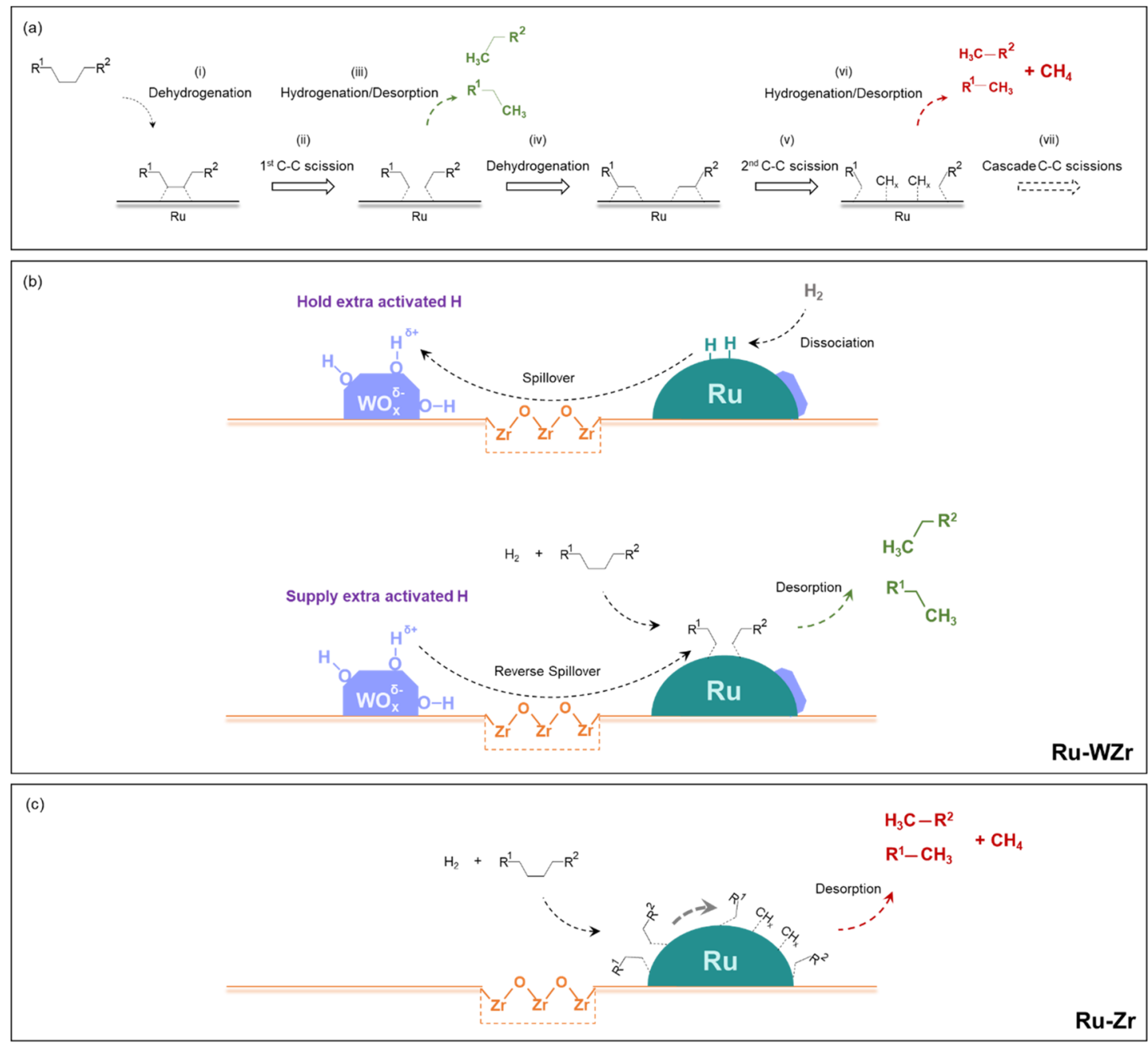

$a_{a}$, Proposed reaction mechanism of LDPE hydrogenolysis on Ru-based catalysts. $\mathrm{R}^{1}, \mathrm{R}^{2}=\mathrm{C}_{n} \mathrm{H}_{2 n+1}(n \geq 0)$ alkyl groups. b, Selective pathway on $\mathrm{Ru}-\mathrm{WZr}$ catalysts induced by $\sim 1 \mathrm{~nm}$, slightly reduced $\left(\mathrm{WO}_{x}\right)_{\mathrm{n}}$ clusters. c, Non-selective pathway on $\mathrm{Ru}-\mathrm{Zr}$ in the absence of $\mathrm{WO}_{x}$. The proximity of $\mathrm{Ru}$ and $\mathrm{WO}_{x}$ is not depicted exactly as $\mathrm{WO}_{x}$ covers some of the $\mathrm{Ru}$. The reverse spillover mechanism is meant to include also other aspects, such as interfacial sites and a change in polymer-surface interactions.

that the Ru-catalyzed $\mathrm{C}-\mathrm{C}$ bond activation, which is ratelimiting at high pressures, is not modified by $\mathrm{WO}_{x}$ incorporation. This is consistent with the $n$-hexane model reaction results (Figure S7c), which show an identical TOF per $\mathrm{C}-\mathrm{C}$ bond scission over $\mathrm{Ru}-\mathrm{Zr}$ and the two $\mathrm{Ru}-\mathrm{WZr}$ catalysts (see detailed discussion in Supporting Information). Our structural characterizations show little difference in particle size of Ru-Zr and Ru-15WZr catalysts (see EXAFS results in Table S4), and XPS data also provide no evidence of electronic modification of $\mathrm{Ru}$ by $\mathrm{WO}_{x}$. These findings altogether indicate that the contribution of $\mathrm{Ru}$ is not impacted by the $\mathrm{WO}_{x}$ incorporation. The benefit of $\mathrm{Ru}-\mathrm{WZr}$ catalysts in $\mathrm{H}_{2}$ deficient environments may arise from additional hydrogen, polymersurface interaction, and/or interfacial sites created on these catalysts. The data suggests that the $\left(\mathrm{WO}_{x}\right)_{\mathrm{n}}$ clusters may supply extra $\mathrm{H}$ via reverse-spillover to facilitate the rate-limiting hydrogenation/desorption (iii) on the $\mathrm{Ru}$ surface or the interface or modify the polymer-catalyst interactions, enhancing both activity and selectivity and effectively changing the mechanism from Scheme 1c to Scheme 1b. We elaborate on this point next.

\section{Role of Hydrogen on Ru-WZr Catalysts}

TPR-MS and $\mathrm{H}_{2}$-TPD-MS measurements provide further insights into the enhanced performance of Ru-15WZr. TPRMS results (Figure 5a) show that, at low temperatures (300$600 \mathrm{~K}), \mathrm{Ru}-\mathrm{Zr}$ consumes roughly $0.6 \mathrm{mmol} \mathrm{H}_{2} / \mathrm{g}$, primarily due to the reduction of surface $\mathrm{Ru}$ oxides and $\mathrm{Ru}-15 \mathrm{WZr}$ consumes an extra of $0.3 \mathrm{mmol} \mathrm{H}_{2} / \mathrm{g}$. This additional hydrogen likely remains on the catalyst at least until $600 \mathrm{~K}$ because the formation of $\mathrm{H}_{2} \mathrm{O}$ below $600 \mathrm{~K}$ on both $\mathrm{Ru}-\mathrm{Zr}$ and $\mathrm{Ru}-15 \mathrm{WZr}$ is quite similar (Figure S11). The reduction of $\mathrm{WO}_{x}$ on $15 \mathrm{WZr}$ consumes $\sim 1.9 \mathrm{mmol} \mathrm{H}_{2} / \mathrm{g}$. It occurs at a much higher temperature of $\sim 900 \mathrm{~K}$ than Ru-15WZr. On the latter, the $\mathrm{WO}_{x}$ reduction peak is much broader and starts at much lower temperatures of $\sim 600 \mathrm{~K}$. The lower reduction temperature of $\mathrm{WO}_{x}$ on $\mathrm{Ru}-15 \mathrm{WZr}$ stems from Ru's role. These results indicate a possible hydrogen spillover, where $\mathrm{Ru}$ dissociates $\mathrm{H}_{2}$ and $\mathrm{H}$ diffuses over to the $\left(\mathrm{WO}_{x}\right)_{\mathrm{n}}$ clusters. This extra $\mathrm{H}$ on $\left(\mathrm{WO}_{x}\right)_{\mathrm{n}}$ can be readily available for hydrogenation reactions on metallic $\mathrm{Ru}$ by the reverse spillover mechanism. ${ }^{51}$

TPD-MS results (Figure 5b) show that $\mathrm{H}_{2}$ desorbed from $\mathrm{Ru}-15 \mathrm{WZr}(0.16 \mathrm{mmol} / \mathrm{g})$ is 3 -fold that from $\mathrm{Ru}-\mathrm{Zr}(0.05$ 

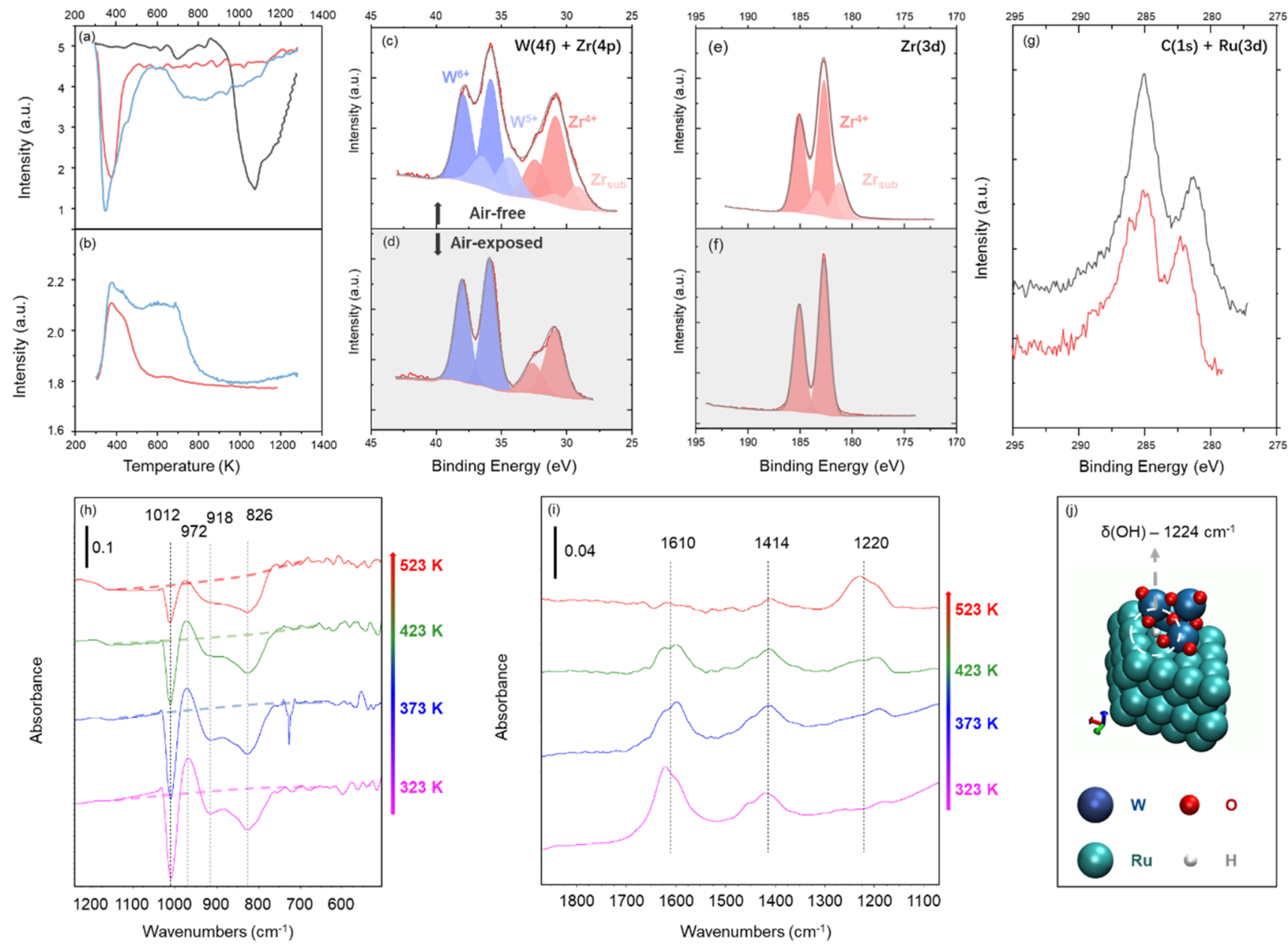

Figure 5. Role of hydrogen on Ru-15WZr catalyst. a, TPR-MS (negative features, $m / z=2$ ). $b, \mathrm{H}_{2}$-TPD-MS (positive features, $m / z=2$ ) measurements on 15WZr (black), Ru-Zr (red), and Ru-15WZr (blue). c-f, XPS spectra of (c, e) air-free and (d, f) air-exposed Ru-15WZr catalyst in the (c, d) W $4 \mathrm{f}+\mathrm{Zr} 4 \mathrm{p}$ region and (e, f) $\mathrm{Zr} 3 \mathrm{~d}$ region. Contributions from $\mathrm{W}^{6+}, \mathrm{W}^{5+}, \mathrm{Zr}^{4+}$, and partially reduced $\mathrm{ZrO}_{2}$ were deconvoluted and are illustrated in purple, light purple, red, and light red, respectively. g, XPS spectra of air-free (black trace) and air-exposed (red trace) Ru-15WZr in the region of $\mathrm{C} 1 \mathrm{~s}$ and $\mathrm{Ru} 3 \mathrm{~d}$ for Ru metal, $\mathrm{RuO}_{2}$, and/or $\mathrm{RuO}_{2} \cdot x \mathrm{H}_{2} \mathrm{O}$. All catalysts for XPS were pretreated in $10 \% \mathrm{H}_{2} / \mathrm{He}$ at $523 \mathrm{~K}$ for $1 \mathrm{~h}$ with the air-exposed samples being equilibrated in air at room temperature and the air-free samples being immediately transferred (at room temperature) for measurements without exposing to air $\left(P_{\mathrm{O}_{2}}<1000 \mathrm{ppm}\right)$ using a vacuum transfer vessel. $\mathrm{h}$ and $\mathrm{i}$, Difference IR spectra of Ru$15 \mathrm{WZr}$ at (pink) $323 \mathrm{~K}$, (blue) $373 \mathrm{~K}$, (green) $423 \mathrm{~K}$, and (red) $523 \mathrm{~K}$ collected upon exposure to steady-state $10 \% \mathrm{H}_{2}$ flow carried by $60 \mathrm{sccm} \mathrm{He}$. $\mathrm{h}$, Stretching vibration regime of $\mathrm{W}=\mathrm{O}$ and $\mathrm{W}-\mathrm{O}-\mathrm{W}$ groups. $\mathrm{i}$, Bending vibration regime of $\mathrm{O}-\mathrm{H}$ groups. Difference spectra were obtained by subtracting the absorbance spectra collected prior to $\mathrm{H}_{2}$ exposure from the spectra post- $\mathrm{H}_{2}$ exposure at each temperature. Horizontal dashed lines represent estimated baselines. j, Simulated bending vibration modes of hydroxyl on a $\mathrm{W}_{4} \mathrm{O}_{12}$ cluster, supported on $\mathrm{Ru}(0001)$.

$\mathrm{mmol} / \mathrm{g}$ ), with a higher $\mathrm{H}$ binding energy, based on the desorption temperatures that extend beyond those of $\mathrm{Ru}-\mathrm{Zr}$ and up to $800 \mathrm{~K}$. DFT calculations (Table S6) of a $\mathrm{W}_{4} \mathrm{O}_{12}$ cluster on $\mathrm{Ru}$ (0001), chosen as a model structure, confirms that the surface $\mathrm{H}$ on $\mathrm{W}-\mathrm{OH}$ groups is bound significantly more strongly $\left(E_{\text {binding }}=-1.43,-1.29\right.$, and $\left.-1.05 \mathrm{eV}\right)$ than on the $\mathrm{Ru}$ sites $\left(E_{\text {binding }}=-0.93,-0.82\right.$, and $\left.-0.44 \mathrm{eV}\right)$. In contrast, a Ru-20WSi catalyst does not possess synergistic features in TPR and TPD measurements (Figure S12); at the same time, it lacks highly dispersed $\left(\mathrm{WO}_{x}\right)_{\mathrm{n}}$ clusters $(\mathrm{XRD}$ and Raman, Figure S13) and does not suppress methane formation (Figure S14).

Air-free XPS spectra in the $\mathrm{W} 4 \mathrm{f}+\mathrm{Zr} 4 \mathrm{p}$ region (Figure $5 \mathrm{c}$ ) and $\mathrm{Zr} 3 \mathrm{~d}$ region (Figure 5e) were collected after pretreating $\mathrm{Ru}-15 \mathrm{WZr}$ at $523 \mathrm{~K}$ and 1 bar in a $10 \% \mathrm{H}_{2}$ flow. Deconvoluted and benchmarked spectra against the air-equilibrated ones are shown in Figure 5d,f. Both the air-exposed $\mathrm{W}$ and $\mathrm{Zr}$ oxides are at the highest valence, evidenced by doublets for $\mathrm{W} 4 \mathrm{f}$ at 38.0 and $36.0 \mathrm{eV}, \mathrm{Zr} 4 \mathrm{p}$ at 32.5 and $30.9 \mathrm{eV}$ (Figure $5 \mathrm{~d}$ ), and $\mathrm{Zr} 3 \mathrm{~d}$ at 185.0 and $182.7 \mathrm{eV}$ (Figure 5f). Air-free Ru-15WZr (Figure $5 c)$ shows reduction bands associated with both $\mathrm{W}^{5+}$ cations $^{52}$ $(36.4$ and $34.4 \mathrm{eV}$ ) and $\mathrm{Zr}$ suboxides (30.7 and $29.1 \mathrm{eV}$ for $\mathrm{Zr}$ $4 p$ and 183.4 and $181.2 \mathrm{eV}$ for $\mathrm{Zr} 3 \mathrm{~d}$ ). Deconvolution of the $\mathrm{W}^{4+}$ center is impossible due to overlap with the $\mathrm{Zr} 4 \mathrm{p}$ and is omitted from the analysis. Since $\left(\mathrm{WO}_{x}\right)_{\mathrm{n}}$ clusters are predominantly $\sim 1 \mathrm{~nm}$ in size (within photoelectron escape depth), we estimate that roughly $30 \%$ of $\mathrm{W}^{6+}$ centers are reduced to 5+ (or lower) oxidation state based on the deconvolution area ratios.

Since little water forms from $\mathrm{WO}_{x}$ reduction up to $600 \mathrm{~K}$, based on the TPR-MS on Ru-15WZr (Figure S11), we envision that hydrogen spillover leads to $\mathrm{H}^{\delta+}$ interacting with the Lewis basic oxygen atoms $(\mathrm{W}=\mathrm{O}$ or $\mathrm{W}-\mathrm{O}-\mathrm{W})$ while injecting electrons into the $\mathrm{W}^{6+}$ centers to lower their oxidation state (Scheme 1b), similar to frustrated Lewis pairs. ${ }^{53,54}$ Since the degree of hydrogen incorporation is in part 
determined by the ability to delocalize the injected electrons into the conjugated base, ${ }^{43}$ i.e., the $\left(\mathrm{WO}_{x}\right)_{\mathrm{n}}$ clusters, it is not surprising then that the hydrogen storage capacity is associated with the $\sim 1 \mathrm{~nm}\left(\mathrm{WO}_{x}\right)_{\mathrm{n}}$ clusters on $\mathrm{Ru}-15 \mathrm{WZr}$ rather than bulk crystallites on Ru-20WSi. The slight reduction of the $\mathrm{ZrO}_{2}$ surface may also result from hydrogen spillover. ${ }^{55}$ Since $\mathrm{Ru}$ and $\mathrm{WO}_{x}$ species are highly dispersed on $\mathrm{ZrO}_{2}$ (Figure 3), the partially reduced $\mathrm{ZrO}_{2}$ sites may be implicated by bridging $\mathrm{H}^{\delta+}$ species and electrons between $\mathrm{Ru}$ and $\left(\mathrm{WO}_{x}\right)_{\mathrm{n}}$ islands (Scheme 1b). Such an effect is impossible on nonsemiconducting supports, such as $\mathrm{SiO}_{2}$ (Scheme $\mathrm{S} 1$ ).

XPS bands associated with $\mathrm{Ru} 3 \mathrm{~d}$ (Figure 5g) are complicated due to $\mathrm{C} 1 \mathrm{~s}$ overlaps and interference between the $\mathrm{Ru}$ metal and hydrated/dehydrated oxides. ${ }^{56}$ By subtracting the two Ru-15WZr spectra with and without air exposure, contributions of the metallic $\mathrm{Ru} 3 \mathrm{~d}_{5 / 2}$ band $(\sim 280 \mathrm{eV})$ become evident in the air-free sample; yet, $\mathrm{Ru}$ is likely to remain slightly oxidized in the air-free sample, judging by the bandwidth and according to the literature on $\mathrm{Ru} / \mathrm{TiO}_{2}$. ${ }^{57}$

We performed in situ transmission FTIR measurements on $\mathrm{Ru}-15 \mathrm{WZr}$ catalyst under relevant reaction conditions (323$523 \mathrm{~K}$ and 1 bar in $10 \% \mathrm{H}_{2} / \mathrm{He}$ flow) and obtained difference absorbance spectra by subtracting the collected spectra before and after steady-state $\mathrm{H}_{2}$ exposure at each temperature (see Figure S15 for spectra overview and peak assignments). All samples were pretreated in $\mathrm{H}_{2}$ and purged in $\mathrm{He}$ at $623 \mathrm{~K}$ to ensure water formation does not interfere with the results acquired at lower temperatures.

Upon $\mathrm{H}_{2}$ exposure, the difference IR features from 323 to $523 \mathrm{~K}$ in the $\mathrm{W} / \mathrm{O}$ stretching regime (Figure $5 \mathrm{~h}$ ) are similar to a decrease in the dehydrated $\nu(\mathrm{W}=\mathrm{O}) \operatorname{mode}^{58}\left(1012 \mathrm{~cm}^{-1}\right)$ and an increase in the hydrated $\nu(\mathrm{W}=\mathrm{O}) \operatorname{mode}^{58}\left(972 \mathrm{~cm}^{-1}\right)$. Since pretreatments rule out water formation, we assign this band shift to $\mathrm{W}=\mathrm{O}$ hydrogen bonding with the proximal $\mathrm{H}^{\delta+}$ species and/or $\mathrm{OH}$ groups (i.e., $\mathrm{W}=\mathrm{O} \cdots \mathrm{H}$ and/or $\mathrm{W}=\mathrm{O} \cdots$ $\mathrm{H}-\mathrm{O}-\mathrm{W})$. The relative intensity of hydrated $(+) /$ dehydrated (-) $\nu(\mathrm{W}=\mathrm{O})$ bands decreases at higher temperatures, suggesting consumption of the $\mathrm{W}=\mathrm{O}$ bonds at high temperatures and probable transformation into $\mathrm{W}-\mathrm{OH}$ species with formal $\mathrm{O}-\mathrm{H}$ bonds. The broad spectral envelope at 918 and $826 \mathrm{~cm}^{-1}$ can have contributions from both $\nu(\mathrm{W}-\mathrm{O}-\mathrm{Zr})$ and $\nu(\mathrm{W}-\mathrm{O}-\mathrm{W})$ modes, ${ }^{59}$ as in the multiwavelength Raman approach on transitional metal oxides. ${ }^{60}$ The decrease in the difference absorbance (Figure $5 \mathrm{~h}$ ) is possibly due to electron delocalization on $\mathrm{WO}_{x}^{\delta-}$ species induced by charge separation of spillover hydrogen. Similar trends in the overtone regime at $\sim 2000 \mathrm{~cm}^{-1}$ further corroborate the above changes (Figure S16). The same methodology on a benchmark $15 \mathrm{WZr}$ sample shows 1-2 orders of magnitude weaker changes in difference spectra (Figure S17) when the intensities of absolute absorbance spectra are comparable (Figure S18a,b). Moreover, the relative band areas of hydrated $(+) /$ dehydrated $(-) \mathrm{W}=\mathrm{O}$ features do not change significantly at elevated temperatures, suggesting that no $\mathrm{W}=\mathrm{O} / \mathrm{W}-\mathrm{OH}$ transformations occur without hydrogen spillover from $\mathrm{Ru}$. Difference features associated with $\nu(\mathrm{W}-\mathrm{O}-\mathrm{Zr})$ and $\nu(\mathrm{W}-\mathrm{O}-\mathrm{W})$ modes are absent, suggesting no charge separation on the $\left(\mathrm{WO}_{x}\right)_{\mathrm{n}}$ clusters without $\mathrm{Ru}$. The $\mathrm{W} / \mathrm{O}$ vibrational changes in response to $\mathrm{H}_{2}$ exposure on both $\mathrm{Ru}-15 \mathrm{WZr}$ and $15 \mathrm{WZr}$ catalysts were subsequently confirmed by in situ Raman measurements (Figure S18c-f) performed under the same conditions.

Consistent difference absorbance for the $\delta(\mathrm{OH})$ modes on $\mathrm{Ru}-15 \mathrm{WZr}$ is depicted in Figure 5i. The corresponding $\nu(\mathrm{OH})$ modes exhibit very broad features at $\sim 3000 \mathrm{~cm}^{-1}$ due to $\mathrm{H}$ bonding and are shown in Figure S16b. In the $\delta(\mathrm{OH})$ regime, the band at $\sim 1610 \mathrm{~cm}^{-1}$ resembles the deformation vibrations of water hydroxyls. In the absence of molecular water (Figure S19), we ascribe this feature to water-like surface species ${ }^{61}$ that release molecular $\mathrm{H}_{2}$, instead of $\mathrm{H}_{2} \mathrm{O}$, upon heating or evacuation. The difference features at $\sim 1414$ and $1200 \mathrm{~cm}^{-1}$ were previously assigned to $\delta(\mathrm{OH})$ modes of $\mathrm{W}-\mathrm{OH}$ interaction with surface oxygen atoms to a different degree. $^{62-64}$ The band at $1610 \mathrm{~cm}^{-1}$ diminishes at elevated temperatures due to thermal instability. ${ }^{37}$ The $1414 \mathrm{~cm}^{-1}$ feature remains stable and is ultimately reduced at $523 \mathrm{~K}$. At high temperatures, a third, quite unusual $\delta(\mathrm{OH})$ band emerges at $\sim 1220 \mathrm{~cm}^{-1}$. DFT calculations of a $\mathrm{W}_{4} \mathrm{O}_{12}$ cluster on $\mathrm{Ru}$ (0001), as a model structure (Figure $5 \mathrm{j}$ ), reveal that this unique $\delta(\mathrm{OH})$ mode may be assigned to $\mathrm{W}-\mathrm{OH}$ groups adjacent to a $\mathrm{W}=\mathrm{O}$ group (Movie 1; details in Supporting Information). This bending vibration is absent in $\mathrm{W}_{4} \mathrm{O}_{12}$ without $\mathrm{Ru}$ (Movie 2). We observed the $\sim 1220 \mathrm{~cm}^{-1}$ band grows with increasing temperature, whereas the 1600 and 1414 $\mathrm{cm}^{-1}$ bands decrease in unison (Figure 5i). This is consistent with the decrease in the relative band areas of hydrated $(+) /$ dehydrated $(-) \nu(\mathrm{W}=\mathrm{O})$ features (Figure $5 \mathrm{~h}$ ), which suggest the transformation from $\mathrm{W}=\mathrm{O}$ to $\mathrm{W}-\mathrm{O}-\mathrm{H}$ bonds. Experiments on $15 \mathrm{WZr}$ or Ru-Zr (Figure S19) hardly give any such difference features, highlighting the $\mathrm{Ru}-\mathrm{WO}_{x}$ synergy in Ru-WZr. The $\delta(\mathrm{OH})$ bands at $\sim 1610,1414$, and $1220 \mathrm{~cm}^{-1}$ were definitively assigned by replicating experiments using molecular deuterium (Figure S20). The observed $\delta(\mathrm{OD})$ wavenumbers agree well with those derived from the corresponding $\delta(\mathrm{OH})$ modes calculated using reduced mass. Relaxation of the $\mathrm{H}_{2}$-equilibrated $\mathrm{Ru}-15 \mathrm{WZr}$ catalyst (Figure S21) shows that all the different features associated with $\nu(\mathrm{W} /$ $\mathrm{O})$ and $\delta(\mathrm{OH})$ modes nearly reversed to the original states when $\mathrm{H}_{2}$ was removed from the feed stream at $523 \mathrm{~K}$. This suggests that the extra $\mathrm{H}$ stored in hydroxyls is highly mobile, can reverse spillover back to the $\mathrm{Ru}$ surface, and may be subject to recombinative desorption of molecular $\mathrm{H}_{2}$ (TPD, Figure $5 b)$.

Collectively, multiple characterization approaches and DFT calculations corroborate the presence of an extra amount of highly mobile and active $\mathrm{H}$ species on the $\mathrm{Ru}-\mathrm{WZr}$ catalysts. These $\mathrm{H}$ species can undergo reversible spillover between $\mathrm{Ru}$ and $\left(\mathrm{WO}_{x}\right)_{\mathrm{n}}$ clusters, aiding hydrogenation and desorption (iii, Scheme $1 \mathrm{~b})$, enhancing activity and selectivity in LDPE hydrogenolysis under $\mathrm{H}_{2}$ deficient conditions. The correlation of $\mathrm{H}$ storage with selectivity is unambiguous. However, direct proof of the implication of the reverse spillover mechanism is not possible at this moment. We hypothesize that new interfacial sites created by $\mathrm{OH}$ and modified polymer-catalyst interactions could also possibly be at play. Further work is needed to dissect the precise mechanism.

\section{DISCUSSION}

We demonstrated that $\mathrm{Ru}-\mathrm{WZr}$ catalysts are highly active and selective for LDPE hydrogenolysis at mild conditions (low temperatures, short times, a low catalyst to polymer mass ratio). Importantly, this performance extends to real-world plastic consumables, such as LDPE bottles, cling wraps, and pipettes, where reaction times could be shorter and conversions higher. Excitingly, they significantly suppress low-value methane formation and produce higher molecular weight fuels and wax/lubricant base-oils compared to $\mathrm{Ru} / \mathrm{C}$ 
and $\mathrm{Ru}$ /zeolites. They are also superior to $\mathrm{Ru}-\mathrm{Zr}$ and $\mathrm{Ru}-\mathrm{WSi}$ catalysts, demonstrating the $\mathrm{WO}_{x}$ and $\mathrm{ZrO}_{2}$ support's profound role. The $\mathrm{WO}_{x}$ addition leverages Ru's high hydrogenolysis activity while overcoming its extensive chain cracking to methane. Characterization and DFT calculations confirm that the highly dispersed $\left(\mathrm{WO}_{x}\right)_{\mathrm{n}}$ clusters store $\mathrm{H}$ in surface hydroxyls by the spillover of $\mathrm{H}$ from the $\mathrm{Ru}$ active phase that dissociates molecular $\mathrm{H}_{2}$. $\mathrm{WO}_{x}$ increases the catalyst hydrogen storage capacity essential for hydrogenating longchain alkyl intermediates through reverse spillover to Ru or by creating new interfacial sites and/or modifying the catalystpolymer interactions, leading to their desorption before they get overcracked. This novel mechanism of hydrogen storage overcomes significant compression costs associated with high $\mathrm{H}_{2}$ pressures and opens up possibilities for materials design to further engineer plastics recycling.

\section{MATERIALS AND METHODS}

\section{Preparation of Ru-WZ Catalysts}

Ruthenium supported on tungstated zirconia (Ru-WZr) was synthesized using the successive incipient wetness impregnation method. The tungstated zirconia (WZr) support was prepared by impregnation of zirconium oxyhydroxide $\left(\mathrm{ZrO}_{x}(\mathrm{OH})_{4-2 x}\right)$ with a solution of ammonium metatungstate hydrate $\left(\left(\mathrm{NH}_{4}\right)_{6} \mathrm{H}_{2} \mathrm{~W}_{12} \mathrm{O}_{40}\right.$. $x \mathrm{H}_{2} \mathrm{O}$, Aldrich, $\left.99.99 \%\right) . \mathrm{ZrO}_{x}(\mathrm{OH})_{4-2 x}$ was made by hydrolysis of a zirconyl chloride octahydrate $\left(\mathrm{ZrOCl}_{2} \cdot 8 \mathrm{H}_{2} \mathrm{O}\right.$, Aldrich, $\left.98 \%\right)$ solution using ammonium hydroxide $\left(\mathrm{NH}_{4} \mathrm{OH}\right.$, Aldrich, $28-30 \mathrm{wt} \%$ in $\left.\mathrm{H}_{2} \mathrm{O}\right)$. Both solutions were added dropwise in stirred water at $\mathrm{pH}$ of 10 . The suspension was aged under vigorous stirring for $12 \mathrm{~h}$, followed by alternating filtration and rinsing steps until $\mathrm{Cl}^{-}$ions were no longer detectable in the filtrate. $\mathrm{ZrO}_{x}(\mathrm{OH})_{4-2 x}$ was dried at $383 \mathrm{~K}$ in static air for $12 \mathrm{~h}$ and then impregnated with the $\left(\mathrm{NH}_{4}\right)_{6} \mathrm{H}_{2} \mathrm{~W}_{12} \mathrm{O}_{40} \cdot x \mathrm{H}_{2} \mathrm{O}$ solution, followed by drying at $383 \mathrm{~K}$ for $12 \mathrm{~h}$ and calcination in static air at $1073 \mathrm{~K}$ for $3 \mathrm{~h}(2 \mathrm{~K} / \mathrm{min}$ ramp $)$. WZr supports loaded with 15 and $25 \mathrm{wt} \% \mathrm{WO}_{3}$ are denoted as $15 \mathrm{WZr}$ and $25 \mathrm{WZr}$. The asprepared WZr support was subsequently impregnated with a calculated amount of ruthenium(III) nitrosyl nitrate solution $\left(\mathrm{Ru}(\mathrm{NO})\left(\mathrm{NO}_{3}\right)_{x}(\mathrm{OH})_{3-x}\right.$, Aldrich, $\left.1.5 \mathrm{wt} \% \mathrm{Ru}\right)$ to achieve 5 wt \% nominal metal loading. The resulting slurry was dried at $383 \mathrm{~K}$ for 12 $\mathrm{h}$ and then subjected to a $2 \mathrm{~h}$ reduction treatment, carried out in a tubular reactor using $10 \% \mathrm{H}_{2}$ in a $100 \mathrm{sccm} \mathrm{He}$ carrier gas at $523 \mathrm{~K}$. The control catalysts, Ru supported on bare zirconia, tungstated silica, ceria, $\mathrm{HY}$ zeolite, and [Al] MCM-41 material ( $\mathrm{Ru}-\mathrm{Zr}, \mathrm{Ru}-\mathrm{WSi}$, Ru-Ce, $\mathrm{Ru}-\mathrm{HY}$, and $\mathrm{Ru}-[\mathrm{Al}] \mathrm{MCM}-41)$, were prepared by the same $\mathrm{Ru}$ impregnation procedure. Zirconia was prepared by calcining $\mathrm{ZrO}_{x}(\mathrm{OH})_{4-2 x}$ in air at $823 \mathrm{~K}$ for $3 \mathrm{~h}$, WSi was prepared by the same procedure as $\mathrm{WZr}$ except for using amorphous fumed silica $\left(175-225 \mathrm{~m}^{2} / \mathrm{g}\right.$, Alfa Aesar). Ceria (Sigma-Aldrich, Product No.: 700290), $\mathrm{HY}\left(\mathrm{Si} / \mathrm{Al}_{2}=30\right.$, Zeolyst $)$, and $[\mathrm{Al}] \mathrm{MCM}-41\left(\mathrm{Si} / \mathrm{Al}_{2}=25\right.$, ACS Material) were pretreated at $723 \mathrm{~K}$ in air for $2 \mathrm{~h}$ prior to $\mathrm{Ru}$ impregnation. A 5 wt \% Ru on carbon catalyst (Ru-C, Sigma-Aldrich, 206180) was directly purchased from the vendor. Since all catalysts used in this study have the same $5 \mathrm{wt} \% \mathrm{Ru}$ nominal loading, this value of $5 \%$ is omitted throughout the main text.

\section{Reactivity Studies for LDPE Hydrogenolysis}

Prior to the reactivity measurements, all catalysts were prereduced $e x$ situ in a continuous follow reactor at $523 \mathrm{~K}$ for $1 \mathrm{~h}(10 \mathrm{~K} / \mathrm{min}$ ramping rate) using $10 \% \mathrm{H}_{2}$ in $100 \mathrm{sccm}$ He flow. The catalysts were cooled down to room temperature, briefly exposed to air, and mixed with $2 \mathrm{~g}$ of low-density polyethylene $\left(M_{\mathrm{w}} \sim 76 \mathrm{kDa}\right.$, Sigma-Aldrich, Product No. 428043) using a typical LDPE-to-catalyst mass ratio of 40. The mixture was then transferred into a $50 \mathrm{~mL}$ stainless-steel Parr reactor together with a $700 \mu \mathrm{L}$ stir bar. The sealed reactor was purged five times with $\mathrm{H}_{2}$ at $30 \mathrm{bar}$ and then charged to $30 \mathrm{bar}$ (standard temperature and pressure, STP) for the reaction. The reactor was quickly heated up to $523 \mathrm{~K}$ in $20 \mathrm{~min}$, maintained at $523 \mathrm{~K}$ for $2 \mathrm{~h}$ under stirring at $500 \mathrm{rpm}$ (free of external $\mathrm{H}_{2}$ diffusion limitation; higher stirring rates did not change the reactivity), and then quenched in a water-ice bath to below $283 \mathrm{~K}$ for product collection. Reaction reproducibility is verified using five independent batches of $\mathrm{Ru}-\mathrm{Zr}$ and Ru-15WZr catalysts synthesized over 6 months (Figure S22). Hydrogenolysis of single-use LDPE bottles (H-B Instrument, Cat No.: 106260005), cling wraps (Clorox, Glad CLO00020), and pipettes (Fisher Scientific, Cat No. 13-711-7M) were performed following the same procedure. The substances were trimmed into $\sim 5$ $\times 5 \mathrm{~mm}^{2}$ pieces prior to mixing with the catalyst.

\section{$n$-Hexane Hydrogenolysis}

The steady-state reaction rates for $n$-hexane (Aldrich, $\geq 99 \%$ ) hydrogenolysis were measured at 1 bar and $523 \mathrm{~K}$ in a continuous flow reactor that consisted of an 18-in. long, 1/4-in. ID quartz tube placed vertically in a tube furnace. The catalyst bed (typically $100 \mathrm{mg}$ ) was diluted 100 times using inert $\mathrm{ZrO}_{2}$ supports and held in place by quartz-wool plugs and coarse quartz pellets loaded on both ends of the catalyst bed. The reactor was custom-made to insert a thermocouple, protected by a quartz protection sleeve, at the center of the catalyst bed. Before the kinetic measurements, the catalyst was pretreated at $523 \mathrm{~K}\left(10 \mathrm{~K} / \mathrm{min}\right.$ ramping rate) for $1 \mathrm{~h}$ in $10 \% \mathrm{H}_{2}$ in $100 \mathrm{sccm}$ He. $n$-Hexane (1-2\%) was injected into a He carrier flow using a syringe pump (New Era Pump System) and mixed with $\mathrm{H}_{2}$ flow before entering the reactor.

\section{Product Analysis}

Products from the probe reaction of $n$-hexane hydrogenolysis were analyzed online using an FID gas chromatography equipped with an Agilent HP-Plot GC column. For the LDPE hydrogenolysis reactions, gaseous products, typically $\mathrm{C} 1-\mathrm{C} 6$, from the Parr reactor headspace were sampled at $283 \mathrm{~K}$ using a $1 \mathrm{~L}$ Tedlar bag and analyzed using the aforementioned GC. Quantification was done using standard calibration mixtures. Hydrocarbon products, typically C4-C35, were extracted from the liquid-solid residuals using a $20 \mathrm{~mL}$ of dichloromethane $\left(\mathrm{CH}_{2} \mathrm{Cl}_{2}\right.$, Fisher Scientific, ACS grade) solution with $20 \mathrm{mg}$ of $n$-octacosane (external standard, $n$-C28, TCI chemicals, $>98 \%$ ). Since the reaction produces a small amount of $n-\mathrm{C} 28$, the signal of internal standard is calculated from the raw $n$-C28 signal minus the estimated $n-\mathrm{C} 28$ product signal using an average of $n$-C27 and $n$-C29. The soluble products were analyzed using GC-MS (Agilent, DB-1 column) for identification and GC-FID (Agilent HP-1 column) for quantification. A representative raw GC trace is shown in Figure S23. Calibration of GC signals was conducted using normal alkanes standard mixtures, and alkane isomers were assumed to have the same calibration factor as the corresponding normal alkanes. The catalyst and remaining solids were filtered, dried in air for $24 \mathrm{~h}$, and weighed prior to further characterization.

The yield of product alkanes with $i$ carbons $\left(C_{i}\right)$ was calculated using the following equation:

$$
Y_{i}=\frac{n_{i}}{n_{\text {initial }}}
$$

where $n_{i}$ is the moles of carbon in $C_{i}$, and $n_{\text {initial }}$ is the same in the initial LDPE feedstock. The selectivity of product alkanes with $i$ carbons $\left(C_{i}\right)$ is evaluated from

$$
S_{i}=\frac{Y_{i}}{\sum_{\text {non-solid }} Y_{i}}
$$

Here $\sum_{\text {nonsolid }} Y_{i}$ corresponds to the yield of nonsolid productsnamely, the combined yield of all gaseous and soluble liquid products.

High-resolution differential scanning calorimetry (DSC, Discovery, TA Instruments) measurements were performed to characterize the melting temperature and heat of fusion for pristine LDPE and the solid residues collected after filtration.

\section{Catalyst Characterization}

$\mathrm{X}$-ray diffraction (XRD) patterns of powdered materials were measured using a Bruker D8 diffractometer equipped with a $\mathrm{Cu} \mathrm{K} \alpha$ source. The BET surface area and porosity were measured using $\mathrm{N}_{2}$ as 
the adsorbent at $77 \mathrm{~K}$ with a Micromeritics ASAP 2020 instrument. Raman spectra were obtained with a LabRAM high-resolution Raman spectrometer (HORIBA) equipped with a $\mathrm{He}-\mathrm{Cd}$ excitation UV laser with a wavelength of $325 \mathrm{~nm}$ and a green line solid-state laser with a wavelength of $532 \mathrm{~nm}$. In situ Raman spectroscopy was performed in an environmentally controlled high-temperature cell (Harrick). Elemental analysis was carried out on a wavelength-dispersive X-ray fluorescence spectrometer (WDXRF, Rigaku, Supermini 200) equipped with a high-powered $(200 \mathrm{~W}) \mathrm{X}$-ray tube. For X-ray photoelectron spectroscopy (XPS) analysis, powdered samples were pressed onto $\mathrm{Cu}$ foils. XPS spectra were collected using a Thermo Fisher K-Alpha Instrument equipped with an $\mathrm{Al}(\mathrm{K}) \mathrm{X}$-ray source. Samples used in air-free XPS measurements were pretreated in a tubular flow reactor using $10 \% \mathrm{H}_{2}$ in a $100 \mathrm{sccm} \mathrm{He}$ carrier gas for $2 \mathrm{~h}$ at $523 \mathrm{~K}$. The cooled reactor was then sealed and moved into a glovebox $\left(P_{\mathrm{O} 2}<1000 \mathrm{ppm}\right)$, where the samples were transferred into a designated vacuum vessel for XPS measurements. Selected results of compositional and geometrical characterizations described above are summarized in Table S2.

Bright-field transmission electron microscopy (BF-TEM) was performed with a field emission gun transmission electron microscope (JEOL, JEM-2010F), operated at an accelerating voltage of $200 \mathrm{kV}$. Dark-field scanning transmission electron microscopy was performed with a JEOL NEOARM operating at $200 \mathrm{kV}$. The samples were diluted in isopropanol and deposited on a lacey carbon film on copper grids provided by Electron Microscopy Sciences. The probe current was $120 \mathrm{pA}$ with a condenser lens aperture of $40 \mu \mathrm{m}$ and a camera length of $4 \mathrm{~cm}$. Energy-dispersive X-ray spectroscopy was performed with the same parameters, with the exception of a camera length of 2 $\mathrm{cm}$. Two silicon drift detectors (SDD) provided by JEOL were used, and the maps were obtained with DigitalMicrograph, a software provided by Gatan Inc.

Apparent dispersions of $\mathrm{Ru}$ were measured on a Micromeritics AutoChem II instrument following a customized procedure of $\mathrm{H}_{2}$ chemisorption reported by Iglesia and coworkers. ${ }^{65}$ This method has previously been shown to have an $\mathrm{H}_{2} / \mathrm{Ru}=1$ stoichiometry and is not affected by the reduction history of Ru or SMSI effect. In brief, the sample was pretreated in situ under $10 \% \mathrm{H}_{2} / \mathrm{Ar}$ flow for $1 \mathrm{~h}$ at $523 \mathrm{~K}$ followed by purging in pure Ar flow for $1 \mathrm{~h}$ at $523 \mathrm{~K}$. The sample was cooled under Ar, maintained at $200 \mathrm{~K}( \pm 10 \mathrm{~K})$ using a liquid $\mathrm{N}_{2}-$ ethanol bath, and subsequently treated in a $1 \% \mathrm{O}_{2} / \mathrm{He}$ mixture at 200 $\mathrm{K}$ for $15 \mathrm{~min}$ followed by purging in Ar flow at $200 \mathrm{~K}$ for $15 \mathrm{~min}$. Finally, the sample was heated in Ar flow and maintained at $373 \mathrm{~K}$ for $1 \mathrm{~h}$. Ru dispersions were measured using pulse $\mathrm{H}_{2}$ chemisorption at $373 \mathrm{~K}$. Results from all catalysts used in this study are tabulated in Table S3. Conventional chemisorption of neither $\mathrm{H}_{2}$ nor $\mathrm{CO}$ using simple pulse techniques at room temperature is reliable (Table S7). This is in part due to the activation energy of $\mathrm{H}_{2}$ adsorption on $\mathrm{Ru}$ at room temperature, ${ }^{66}$ especially on catalysts that featured fairly strong metal-support interaction (underestimation of $\mathrm{Ru}$ dispersion) and the fast reaction activation of $\mathrm{CO}$ on the Ru surface (overestimation of $\mathrm{Ru}$ dispersion).

Temperature-programmed reduction (TPR) and temperatureprogrammed desorption (TPD) of adsorbed hydrogen $\left(\mathrm{H}_{2}-\mathrm{TPD}\right)$ were carried out in combination with mass spectroscopy (MS) analysis (Pfeiffer Vacuum Ominstar GSD 301C quadrupole mass spectrometer) using a continuous flow reactor. For TPR-MS measurements, the sample was purged in $\mathrm{He}$ at $523 \mathrm{~K}$ for $1 \mathrm{~h}$ and cooled down to room temperature in He flow. A $60 \mathrm{sccm}, 5 \% \mathrm{H}_{2}$ in He flow was stabilized to steady state for at least $1 \mathrm{~h}$. The TPR measurement was then carried out at a ramping rate of $10 \mathrm{~K} / \mathrm{min}$ from 300 to $1273 \mathrm{~K}$. For $\mathrm{H}_{2}$-TPD analysis, the sample was prereduced in a 60 -sccm, $5 \% \mathrm{H}_{2}$ in $\mathrm{He}$ mixed flow at $523 \mathrm{~K}$ for $1 \mathrm{~h}$, cooled down to room temperature, and purged in a $60-\mathrm{sccm} \mathrm{He}$ flow for at least $1 \mathrm{~h}$ to stabilize the baseline of the $\mathrm{H}_{2}$ MS. The $\mathrm{H}_{2}$-TPD measurement was then carried out using the same ramping procedure as $\mathrm{H}_{2}$-TPD. MS signals were calibrated using a MicroGC (990 MicroGC, Agilent) equipped with an MS5A column. The MS signal for He was used as an internal reference for semiquantification of $\mathrm{H}_{2}$ uptake/desorption.
FTIR transmission spectra were acquired on a Nicolet 8700 spectrometer (Thermo Scientific) equipped with a liquid nitrogen cooled MCT detector and a custom-made Pyrex in situ flow cell sealed with $\mathrm{KBr}$ windows on both ends. Powdered samples were pressed into a self-supported disk $(\sim 12.5 \mathrm{mg}, 1000 \mathrm{PSI})$ and aligned with the laser path using a quartz holder. FTIR measurements were performed to analyze the hydrogen surface species at temperatures ranging from 323 to $523 \mathrm{~K}$. Moisture was removed from the gas feed by a liquid nitrogen trap. In order to eliminate the interferences from bulk reduction or water formation, all samples were prereduced in situ at $623 \mathrm{~K}$ for $1 \mathrm{~h}$ in $10 \% \mathrm{H}_{2}$ carried by $60 \mathrm{sccm}$ He flow and then purged in pure $\mathrm{He}$ at $623 \mathrm{~K}$ for $1 \mathrm{~h}$ to remove adsorbed hydrogen. Difference spectra were obtained at $323,373,423$, and $523 \mathrm{~K}$ by subtracting each reference spectrum collected in He from the steadystate spectrum taken in $\mathrm{H}_{2}$ in $\mathrm{He}$ flow at the same temperature. Experiments with deuterium gas $\left(\mathrm{D}_{2}\right.$, Cambridge Isotope Laboratories, D-99.8\%) with the same methodology were repeated in order to confirm the hydroxyl vibration modes.

FTIR of adsorbed pyridine was also performed to characterize the Brønsted and Lewis acid sites. The sample was pretreated in He flow at 523 for $1 \mathrm{~h}$ and then cooled and maintained at $423 \mathrm{~K}$. The sample was then saturated by pyridine vapor introduced by passing He flow through a bubbler filled with liquid pyridine (Aldrich, 99.8\%). Prior to spectrum acquisition, the sample was purged with pure He flow for 30 min to desorb weakly bonded pyridine thermally.

X-ray absorption spectroscopy (XAS) data were collected for the $\mathrm{Ru}$ K-edge $(22.117 \mathrm{keV})$ at the QAS 7-BM beamline of NSLS-II at Brookhaven National Laboratory. The spectra of the reference $(\mathrm{Ru}$ foil) were measured in transmission mode, while spectra of sample catalysts were recorded in fluorescence mode. Before measurements, the sample was packed in a quartz tube connected to a gas line. Then the catalyst was reduced in $20 \mathrm{~mL} / \mathrm{min}$ flow of a $50 \% \mathrm{H}_{2} / \mathrm{He}$ mixture at $473 \mathrm{~K}$ for $30 \mathrm{~min}$. Spectra were collected after reduction. Spectra were subjected to standard data processing using Athena and Artemis software. ${ }^{67}$

\section{Modeling}

Density functional theory calculations (DFT) were performed by the plane-wave based Vienna ab initio simulation package (VASP), version 5.4.4. ${ }^{68-70}$ The electron-electron exchange and correlation energies were computed using the Perdew, Burke, and Ernzerhof functionals with D3 dispersion corrections developed by Grimme. ${ }^{71,72}$ Core electrons were treated with the projector augmented-wave (PAW) pseudopotentials. ${ }^{68,73}$ The Ru (0001) surface was simulated using a four-layer $4 \times 4$ unit cell. The lattice constant of $\mathrm{Ru}$ was calculated to be $2.725 \AA$, in close agreement with the experimental value of $2.71 \AA^{74}$ The supported $\mathrm{WO}_{3}(0001)$ tetramer was constructed by cleaving a $2 \times 1 \times 1$ unit cell from the monoclinic bulk $\mathrm{WO}_{3}$, which features lattice parameters of $a=5.358, b=5.413$, and $c=7.722 \AA$. The lattice parameters are in good agreement with experimental values of $a=5.28, b=5.16$, and $c=7.66 \AA^{75}$ The bottom two layers of $\mathrm{Ru}$ were held fixed during calculations, whereas the rest of all the atoms were allowed to relax. A vacuum padding between the slabs was set at a height of $16.5 \AA$ to minimize the interaction in the $z$-direction. In addition, dipole corrections were applied normal to the surface. The Brillouin zone was integrated using a $3 \times 3 \times 1 \mathrm{k}$-mesh based on the Monkhorst-Pack method, ${ }^{76}$ with Gaussian smearing of $0.1 \mathrm{eV}$. For the plane-wave set, a cutoff energy of $400 \mathrm{eV}$ was used. Electronic structure calculations were performed iteratively, and electronic structures were converged when the difference in energy between subsequent steps fell below $10^{-6} \mathrm{eV}$. Geometries of adsorbate-metal systems were optimized until the maximum of all forces fell below $0.02 \mathrm{eV} / \AA$. Vibrational modes analysis was carried out using the central finite difference method. In these calculations, atoms were displaced by $0.05 \AA$ in all directions by the VASP default. In the vibrational mode calculations, the adsorbatehydrogen and the $\mathrm{WO}_{3}$ cluster were displaced. 


\section{ASSOCIATED CONTENT}

\section{Supporting Information}

The Supporting Information is available free of charge at https://pubs.acs.org/doi/10.1021/jacsau.1c00200.

LDPE hydrogenolysis on Ru-WZr catalysts (Figure S1, Table S1); catalyst characterization and comparison of LDPE hydrogenolysis reactivity to zeolite supported $\mathrm{Ru}$ (Figures S2-S5, Tables S2-S5); solid residue characterization (Figure S6); steady-state $n$-hexane hydrogenolysis at 1 bar (Figure S7); effect of hydrogen pressure on LDPE hydrogenolysis (Figures S8-10); characterization and DFT calculations on hydrogen effect (Figures S11 and S12, Table S6); comparison of catalyst structure and reactivity to a $\mathrm{Ru}-\mathrm{WSi}$ catalyst (Figures $\mathrm{S} 13$ and S14, Scheme S1); computational infrared vibrational modes over Ru-WZr catalyst (Movies 1 and 2); in situ spectroscopic measurements (Figures S15-S21); materials and methods (Figures S22 and S23, Table S7) (PDF)

Raw data and DFT files (ZIP)

Movie S1 showing the vibrational mode of $\mathrm{O}-\mathrm{H}$ bond bending in a $\mathrm{Ru}-\left(\mathrm{WO}_{3}\right) 4-\mathrm{H}$ system (MP4)

Movie S2 showing the bending mode unique to the $\mathrm{WO}_{3}$ cluster on $\mathrm{Ru}(\mathrm{MP} 4)$

\section{AUTHOR INFORMATION}

\section{Corresponding Author}

Dionisios G. Vlachos - Center for Plastics Innovation, University of Delaware, Newark, Delaware 19716, United States; Department of Chemical and Biomolecular Engineering, University of Delaware, Newark, Delaware 19716, United States; ㅇo orcid.org/0000-0002-6795-8403; Email: vlachos@udel.edu

\section{Authors}

Cong Wang - Center for Plastics Innovation, University of Delaware, Newark, Delaware 19716, United States; (1) orcid.org/0000-0002-0451-344X

Tianjun Xie - Center for Plastics Innovation, University of Delaware, Newark, Delaware 19716, United States

Pavel A. Kots - Center for Plastics Innovation, University of Delaware, Newark, Delaware 19716, United States

Brandon C. Vance - Center for Plastics Innovation, University of Delaware, Newark, Delaware 19716, United States; Department of Chemical and Biomolecular Engineering, University of Delaware, Newark, Delaware 19716, United States

Kewei Yu - Department of Chemical and Biomolecular Engineering, University of Delaware, Newark, Delaware 19716, United States

Pawan Kumar - Department of Materials Science and Engineering, University of Pennsylvania, Philadelphia, Pennsylvania 19104, United States; (1) orcid.org/00000002-5764-2915

Jiayi Fu - Department of Chemical and Biomolecular Engineering, University of Delaware, Newark, Delaware 19716, United States

Sibao Liu - Key Laboratory for Green Chemical Technology of Ministry of Education, School of Chemical Engineering and Technology, Tianjin University, Tianjin 300072, China
George Tsilomelekis - Department of Chemical and Biochemical Engineering, School of Engineering, Rutgers, The State University of New Jersey, Piscataway, New Jersey 08854, United States; O orcid.org/0000-0002-0435-8216

Eric A. Stach - Department of Materials Science and Engineering, University of Pennsylvania, Philadelphia, Pennsylvania 19104, United States; 이이이.org/00000002-3366-2153

Weiqing Zheng - Center for Plastics Innovation, University of Delaware, Newark, Delaware 19716, United States

Complete contact information is available at:

https://pubs.acs.org/10.1021/jacsau.1c00200

\section{Author Contributions}

C.W. and D.G.V. with the support of P.A.K, W.Z., and S.L. developed the conceptual foundations and led the writing and revision of the original manuscript. T.X. performed DFT calculations and analysis. C.W. led the experimental measurements and data analysis. B.C.V. contributed to the reactivity measurements. K.Y. performed the TPD/TPR sorption experiments. J.F. performed the XPS experiments. P.K. and E.A.S. performed and analyzed the HAADF-STEM and EDS elemental mapping. P.K. performed and analyzed the EXAFS results. G.T. participated in spectroscopic measurements and reviewed the results. W.Z. performed and analyzed BF-TEM. All authors wrote, reviewed, and approved the final manuscript. Notes

The authors declare no competing financial interest.

\section{ACKNOWLEDGMENTS}

This work was supported as part of the Center for Plastics Innovation, an Energy Frontier Research Center, funded by the U.S. Dept. of Energy, Office of Science, Office of Basic Energy Sciences, under Award Number DE-SC0021166. The STEM and EDS elemental mapping were performed at the Singh Center for Nanotechnology at the University of Pennsylvania, a member of the National Nanotechnology Coordinated Infrastructure (NNCI) network, which is supported by the National Science Foundation (Grant NNCI-1542153). The authors gratefully acknowledge the use of facilities and instrumentation supported by NSF through the University of Pennsylvania Materials Research Science and Engineering Center (MRSEC) (DMR-1720530). This research used beamline 7-BM (QAS) of the NSLS II, a U.S. DOE Office of Science User Facility operated for the DOE Office of Science by Brookhaven National Laboratory under Contract No. DE-SC0012704. Beamline operations were supported in part by the Synchrotron Catalysis Consortium (U.S. DOE, Office of Basic Energy Sciences, Grant No. DE-SC0012335).

\section{REFERENCES}

(1) Giacovelli, C. Single-Use Plastics: A Roadmap for Sustainability; UNEP: 2018; revised edition, pp vi; 6.

(2) OECD. Improving Plastics Management: Trends, policy responses, and the role of international co-operation and trade; Environmental Policy Paper No. 12; 2018.

(3) Geyer, R.; Jambeck, J. R.; Law, K. L. Production, use, and fate of all plastics ever made. Science Advances 2017, 3 (7), No. e1700782.

(4) U.S. Environmental Protection Agency. Advancing Sustainable Materials Management: Facts and Figures Report; 2020.

(5) Goldman, A. S. Catalytic Alkane Metathesis by Tandem Alkane Dehydrogenation-Olefin Metathesis. Science 2006, 312 (5771), 257261. 
(6) Ellis, L. D.; Orski, S. V.; Kenlaw, G. A.; Norman, A. G.; Beers, K. L.; Román-Leshkov, Y.; Beckham, G. T. Tandem Heterogeneous Catalysis for Polyethylene Depolymerization via an Olefin-Intermediate Process. ACS Sustainable Chem. Eng. 2021, 9 (2), 623-628.

(7) Bäckström, E.; Odelius, K.; Hakkarainen, M. Trash to Treasure: Microwave-Assisted Conversion of Polyethylene to Functional Chemicals. Ind. Eng. Chem. Res. 2017, 56 (50), 14814-14821.

(8) Celik, G.; Kennedy, R. M.; Hackler, R. A.; Ferrandon, M.; Tennakoon, A.; Patnaik, S.; LaPointe, A. M.; Ammal, S. C.; Heyden, A.; Perras, F. A.; et al. Upcycling Single-Use Polyethylene into HighQuality Liquid Products. ACS Cent. Sci. 2019, 5 (11), 1795-1803.

(9) Serrano, D. P.; Aguado, J.; Escola, J. M. Developing Advanced Catalysts for the Conversion of Polyolefinic Waste Plastics into Fuels and Chemicals. ACS Catal. 2012, 2 (9), 1924-1941.

(10) Mark, L. O.; Cendejas, M. C.; Hermans, I. The Use of Heterogeneous Catalysis in the Chemical Valorization of Plastic Waste. ChemSusChem 2020, 13 (22), 5808-5836.

(11) Sharratt, P. N.; Lin, Y.-H.; Garforth, A. A.; Dwyer, J. Investigation of the Catalytic Pyrolysis of High-Density Polyethylene over a HZSM-5 Catalyst in a Laboratory Fluidized-Bed Reactor. Ind. Eng. Chem. Res. 1997, 36 (12), 5118-5124.

(12) Vance, B. C.; Kots, P. A.; Wang, C.; Hinton, Z. R.; Quinn, C. M.; Epps, T. H.; Korley, L. T. J.; Vlachos, D. G. Single Pot Catalyst Strategy to Branched Products via Adhesive Isomerization and Hydrocracking of Polyethylene over Platinum Tungstated Zirconia. Appl. Catal., B 2021, 120483.

(13) Zhao, D.; Wang, X.; Miller, J. B.; Huber, G. W. The Chemistry and Kinetics of Polyethylene Pyrolysis: A Process to Produce Fuels and Chemicals. ChemSusChem 2020, 13 (7), 1764-1774.

(14) Munir, D.; Amer, H.; Aslam, R.; Bououdina, M.; Usman, M. R. Composite zeolite beta catalysts for catalytic hydrocracking of plastic waste to liquid fuels. Materials for Renewable and Sustainable Energy 2020, 9 (2), 9.

(15) Aguado, J.; Sotelo, J. L.; Serrano, D. P.; Calles, J. A.; Escola, J. M. Catalytic Conversion of Polyolefins into Liquid Fuels over MCM41: Comparison with ZSM-5 and Amorphous SiO2-Al2O3. Energy Fuels 1997, 11 (6), 1225-1231.

(16) Aguado, J.; Serrano, D.; San Miguel, G.; Escola, J.; Rodríguez, J. Catalytic activity of zeolitic and mesostructured catalysts in the cracking of pure and waste polyolefins. J. Anal. Appl. Pyrolysis 2007, 78 (1), 153-161.

(17) Chen, C. Y.; O’Rear, D. J.; Leung, P. Molecular Redistribution and Molecular Averaging: Disproportionation of Paraffins via Bifunctional Catalysis. Top. Catal. 2012, 55 (19-20), 1344-1361.

(18) Pyra, K.; Tarach, K. A.; Srębowata, A.; Melián-Cabrera, I.; Góra-Marek, K. Pd-modified beta zeolite for modulated hydrocracking of low-density polyethylene into a paraffinic-rich hydrocarbon fuel. Appl. Catal., B 2020, 277, 119070.

(19) Liu, S.; Kots, P. A.; Vance, B. C.; Danielson, A.; Vlachos, D. G. Plastic waste to fuels by hydrocracking at mild conditions. Science Advances 2021, 7 (17), No. eabf8283.

(20) Bin Jumah, A.; Tedstone, A. A.; Garforth, A. A. Hydrocracking of virgin and post-consumer polymers. Microporous Mesoporous Mater. 2021, 315, 110912 .

(21) Bin Jumah, A.; Anbumuthu, V.; Tedstone, A. A.; Garforth, A. A. Catalyzing the Hydrocracking of Low Density Polyethylene. Ind. Eng. Chem. Res. 2019, 58 (45), 20601-20609.

(22) Hesse, N. D.; White, R. L. Polyethylene catalytic hydrocracking by PtHZSM-5, PtHY, and PtHMCM-41. J. Appl. Polym. Sci. 2004, 92 (2), 1293-1301.

(23) Nakaji, Y.; Tamura, M.; Miyaoka, S.; Kumagai, S.; Tanji, M.; Nakagawa, Y.; Yoshioka, T.; Tomishige, K. Low-Temperature Catalytic Upgrading of Waste Polyolefinic Plastics into Liquid Fuels and Waxes. Appl. Catal., B 2021, 285, 119805.

(24) Rorrer, J. E.; Beckham, G. T.; Román-Leshkov, Y. Conversion of Polyolefin Waste to Liquid Alkanes with Ru-Based Catalysts under Mild Conditions. JACS Au 2021, 1 (1), 8-12.

(25) Zhang, F.; Zeng, M.; Yappert, R. D.; Sun, J.; Lee, Y.-H.; Lapointe, A. M.; Peters, B.; Abu-Omar, M. M.; Scott, S. L.
Polyethylene upcycling to long-chain alkylaromatics by tandem hydrogenolysis/aromatization. Science 2020, 370 (6515), 437-441.

(26) Sánchez-Rivera, K. L.; Huber, G. W. Catalytic Hydrogenolysis of Polyolefins into Alkanes. ACS Cent. Sci. 2021, 7 (1), 17-19.

(27) Tennakoon, A.; Wu, X.; Paterson, A. L.; Patnaik, S.; Pei, Y.; Lapointe, A. M.; Ammal, S. C.; Hackler, R. A.; Heyden, A.; Slowing, I. I.; Coates, G. W.; Delferro, M.; Peters, B.; Huang, W.; Sadow, A. D.; Perras, F. A. Catalytic upcycling of high-density polyethylene via a processive mechanism. Nature Catalysis 2020, 3 (11), 893-901.

(28) Jia, C.; Xie, S.; Zhang, W.; Intan, N. N.; Sampath, J.; Pfaendtner, J.; Lin, H. Deconstruction of high-density polyethylene into liquid hydrocarbon fuels and lubricants by hydrogenolysis over $\mathrm{Ru}$ catalyst. Chem. Catalysis 2021, 1, 437.

(29) Lee, W.-T.; Bobbink, F. D.; Van Muyden, A. P.; Lin, K.-H.; Corminboeuf, C.; Zamani, R. R.; Dyson, P. J. Catalytic hydrocracking of synthetic polymers into grid-compatible gas streams. Cell Reports Physical Science 2021, 2 (2), 100332.

(30) Yuan, C.; Emelianov, D. A.; Varfolomeev, M. A.; Pu, W.; Ushakova, A. S. Oxidation Behavior and Kinetics of Eight C20-C54 n-Alkanes by High Pressure Differential Scanning Calorimetry (HPDSC). Energy Fuels 2018, 32 (7), 7933-7942.

(31) Urabe, Y.; Takamizawa, K. The Determination of The Homologous Purity of Higher Normal Alkanes up to Dohectane with Capillary Gas Chromatography. Polym. J. 1994, 26 (3), 283289.

(32) Shen, L.; Severn, J.; Bastiaansen, C. W. M. Drawing behavior and mechanical properties of ultra-high molecular weight polyethylene blends with a linear polyethylene wax. Polymer 2018, 153, 354-361.

(33) Haynes, W. M. CRC Handbook of Chemistry and Physics; CRC Press: 2014

(34) Luo, X.; Xie, S.; Liu, J.; Hu, H.; Jiang, J.; Huang, W.; Gao, H.; Zhou, D.; Lü, Z.; Yan, D. The relationship between the degree of branching and glass transition temperature of branched polyethylene: experiment and simulation. Polym. Chem. 2014, 5 (4), 1305-1312.

(35) Marinkovic, N.; Sasaki, K.; Adzic, R. Nanoparticle size evaluation of catalysts by EXAFS: Advantages and limitations. Zast. Mater. 2016, 57 (1), 101-109.

(36) Okazoe, S.; Kusada, K.; Wu, D.; Yamamoto, T.; Toriyama, T.; Matsumura, S.; Kawaguchi, S.; Kubota, Y.; Kitagawa, H. Synthesis of $\mathrm{Mo}$ and $\mathrm{Ru}$ solid-solution alloy NPs and their hydrogen evolution reaction activity. Chem. Commun. 2020, 56 (92), 14475-14478.

(37) Solonin, Y. M.; Khyzhun, O. Y.; Graivoronskaya, E. A. Nonstoichiometric Tungsten Oxide Based on Hexagonal WO3. Cryst. Growth Des. 2001, 1 (6), 473-477.

(38) Djaoued, Y.; Priya, S.; Balaji, S. Low temperature synthesis of nanocrystalline WO3 films by sol-gel process. J. Non-Cryst. Solids 2008, 354 (2-9), 673-679.

(39) Zhou, W.; Ross-Medgaarden, E. I.; Knowles, W. V.; Wong, M. S.; Wachs, I. E.; Kiely, C. J. Identification of active $\mathrm{Zr}-\mathrm{WO}$ x clusters on a $\mathrm{ZrO} 2$ support for solid acid catalysts. Nat. Chem. 2009, 1 (9), 722.

(40) Wang, C.; Lee, J. D.; Ji, Y.; Onn, T. M.; Luo, J.; Murray, C. B.; Gorte, R. J. A Study of Tetrahydrofurfuryl Alcohol to 1,5-Pentanediol Over Pt-WOx/C. Catal. Lett. 2018, 148 (4), 1047-1054.

(41) Zhou, W.; Soultanidis, N.; Xu, H.; Wong, M. S.; Neurock, M.; Kiely, C. J.; Wachs, I. E. Nature of Catalytically Active Sites in the Supported WO3/ZrO2 Solid Acid System: A Current Perspective. ACS Catal. 2017, 7 (3), 2181-2198.

(42) Wang, C.; Mao, X.; Lee, J.; Onn, T.; Yeh, Y.-H.; Murray, C.; Gorte, R. A Characterization Study of Reactive Sites in ALDSynthesized WOx/ZrO2 Catalysts. Catalysts 2018, 8 (7), 292.

(43) Iglesia, E.; Barton, D. G.; Soled, S. L.; Miseo, S.; Baumgartner, J. E.; Gates, W. E.; Fuentes, G. A.; Meitzner, G. D. Selective isomerization of alkanes on supported tungsten oxide acids. Stud. Surf. Sci. Catal. 1996, 101, 533-542.

(44) Flaherty, D. W.; Hibbitts, D. D.; Iglesia, E. Metal-Catalyzed CC Bond Cleavage in Alkanes: Effects of Methyl Substitution on 
Transition-State Structures and Stability. J. Am. Chem. Soc. 2014, 136 (27), 9664-9676.

(45) Sinfelt, J. H. Catalytic hydrogenolysis on metals. Catal. Lett. 1991, 9 (3-4), 159-171.

(46) Weisz, P. B. Polyfunctional heterogeneous catalysis. Adv. Catal. 1962, 13, 137-190.

(47) Wang, C.; Li, S.; Mao, X.; Caratzoulas, S.; Gorte, R. J. H-D Exchange of Simple Aromatics as a Measure of Brønsted-Acid Site Strengths in Solids. Catal. Lett. 2018, 148 (11), 3548-3556.

(48) Carter, J.; Cusumano, J.; Sinfelt, J. Hydrogenolysis of n-heptane over unsupported metals. J. Catal. 1971, 20 (2), 223-229.

(49) Oya, S.-I.; Kanno, D.; Watanabe, H.; Tamura, M.; Nakagawa, Y.; Tomishige, K. Catalytic Production of Branched Small Alkanes from Biohydrocarbons. ChemSusChem 2015, 8 (15), 2472-2475.

(50) Nakagawa, Y.; Oya, S. i.; Kanno, D.; Nakaji, Y.; Tamura, M.; Tomishige, K. J. C. Regioselectivity and Reaction Mechanism of RuCatalyzed Hydrogenolysis of Squalane and Model Alkanes. ChemSusChem 2017, 10 (1), 189-198.

(51) Prins, R. Hydrogen spillover. Facts and fiction. Chem. Rev. 2012, 112 (5), 2714-2738.

(52) Wang, C.; Mironenko, A. V.; Raizada, A.; Chen, T.; Mao, X.; Padmanabhan, A.; Vlachos, D. G.; Gorte, R. J.; Vohs, J. M. J. A. C. Mechanistic study of the direct hydrodeoxygenation of $\mathrm{m}$-cresol over WO x-decorated Pt/C catalysts. ACS Catal. 2018, 8 (9), 7749-7759.

(53) Jia, J.; Qian, C.; Dong, Y.; Li, Y. F.; Wang, H.; Ghoussoub, M.; Butler, K. T.; Walsh, A.; Ozin, G. A. Heterogeneous catalytic hydrogenation of $\mathrm{CO} 2$ by metal oxides: defect engineering perfecting imperfection. Chem. Soc. Rev. 2017, 46 (15), 4631-4644. (54) Zhao, X.; Wang, J.; Yang, M.; Lei, N.; Li, L.; Hou, B.; Miao, S.; Pan, X.; Wang, A.; Zhang, T. Selective Hydrogenolysis of Glycerol to 1,3-Propanediol: Manipulating the Frustrated Lewis Pairs by Introducing Gold to Pt/WOx. ChemSusChem 2017, 10 (5), 819-824.

(55) Jung, K.-D.; Bell, A. T. Role of Hydrogen Spillover in Methanol Synthesis over $\mathrm{Cu} / \mathrm{ZrO} 2$. J. Catal. 2000, 193 (2), 207-223.

(56) Morgan, D. J. Resolving ruthenium: XPS studies of common ruthenium materials. Surf. Interface Anal. 2015, 47 (11), 1072-1079.

(57) Coq, B.; Crabb, E.; Warawdekar, M.; Bond, G. C.; Slaa, J. C.; Galvagno, S.; Mercadante, L.; Ruiz, J. G.; Sanchez Sierra, M. C. Catalytic and structural properties of ruthenium bimetallic catalysts: Preparation and characterization. J. Mol. Catal. 1994, 92 (1), 107121.

(58) Ross-Medgaarden, E. I.; Wachs, I. E. Structural determination of bulk and surface tungsten oxides with UV- vis diffuse reflectance spectroscopy and raman spectroscopy. J. Phys. Chem. C 2007, 111 (41), 15089-15099.

(59) Rossmedgaarden, E.; Knowles, W.; Kim, T.; Wong, M.; Zhou, W.; Kiely, C.; Wachs, I. New insights into the nature of the acidic catalytic active sites present in $\mathrm{ZrO} 2$-supported tungsten oxide catalysts. J. Catal. 2008, 256 (1), 108-125.

(60) Drake, T. L.; Stair, P. C. Multiwavelength Raman Spectroscopic Characterization of Alumina-Supported Molybdenum Oxide Prepared by Vapor Deposition. Top. Catal. 2017, 60 (19-20), 1618-1630.

(61) Ishikawa, H.; Kondo, J. N.; Domen, K. Hydrogen adsorption on $\mathrm{Ru} / \mathrm{ZrO} 2$ studied by FT-IR. J. Phys. Chem. B 1999, 103 (16), 3229-3234.

(62) Daniel, M. F.; Desbat, B.; Lassegues, J. C.; Garie, R. Infrared and Raman spectroscopies of rf sputtered tungsten oxide films. J. Solid State Chem. 1988, 73 (1), 127-139.

(63) Daniel, M. F.; Desbat, B.; Lassegues, J. C.; Gerand, B.; Figlarz, M. Infrared and Raman study of WO3 tungsten trioxides and WO3, $\mathrm{xH} 2 \mathrm{O}$ tungsten trioxide tydrates. J. Solid State Chem. 1987, 67 (2), $235-247$.

(64) Spitzin, V. I.; Kabanow, V. J. Anwendung von kinetischen Methoden fur die Untersuchung der Struktur und der Reaktionen der Bildung von hochmolekularen Aquowolframaten. Z. Anorg. Allg. Chem. 1963, 322 (5-6), 248-264.

(65) Iglesia, E.; Soled, S. L.; Fiato, R. A. Fischer-Tropsch synthesis on cobalt and ruthenium. Metal dispersion and support effects on reaction rate and selectivity. J. Catal. 1992, 137 (1), 212-224.
(66) Lin, H.-Y.; Chen, Y.-W. The kinetics of H2 adsorption on supported ruthenium catalysts. Thermochim. Acta 2004, 419 (1-2), 283-290.

(67) Ravel, B.; Newville, M. ATHENA, ARTEMIS, HEPHAESTUS: data analysis for X-ray absorption spectroscopy usingIFEFFIT. J. Synchrotron Radiat. 2005, 12 (4), 537-541.

(68) Kresse, G.; Hafner, J. Ab initiomolecular dynamics for liquid metals. Phys. Rev. B: Condens. Matter Mater. Phys. 1993, 47 (1), 558561.

(69) Kresse, G.; Furthmüller, J. Efficient iterative schemes forab initiototal-energy calculations using a plane-wave basis set. Phys. Rev. B: Condens. Matter Mater. Phys. 1996, 54 (16), 11169-11186.

(70) Kresse, G.; Furthmüller, J. Efficiency of ab-initio total energy calculations for metals and semiconductors using a plane-wave basis set. Comput. Mater. Sci. 1996, 6 (1), 15-50.

(71) Grimme, S.; Antony, J.; Ehrlich, S.; Krieg, H. A consistent and accurate $a b$ initio parametrization of density functional dispersion correction (DFT-D) for the 94 elements H-Pu. J. Chem. Phys. 2010, $132(15), 154104$.

(72) Grimme, S.; Ehrlich, S.; Goerigk, L. Effect of the damping function in dispersion corrected density functional theory. J. Comput. Chem. 2011, 32 (7), 1456-1465.

(73) Kresse, G.; Joubert, D. From ultrasoft pseudopotentials to the projector augmented-wave method. Phys. Rev. B: Condens. Matter Mater. Phys. 1999, 59 (3), 1758-1775.

(74) Held, G.; Menzel, D. The structure of the $\mathrm{p}(\sqrt{ } 3 \times \sqrt{ } 3) \mathrm{R} 30^{\circ}$ bilayer of $\mathrm{D} 2 \mathrm{O}$ on $\mathrm{Ru}(001)$. Surf. Sci. 1994, 316 (1-2), 92-102.

(75) Salje, E. K.; Rehmann, S.; Pobell, F.; Morris, D.; Knight, K. S.; Herrmannsdörfer, T.; Dove, M. T. Crystal structure and paramagnetic behaviour of. J. Phys.: Condens. Matter 1997, 9 (31), 6563.

(76) Monkhorst, H. J.; Pack, J. D. Special points for Brillouin-zone integrations. Phys. Rev. B 1976, 13 (12), 5188-5192. 